\title{
Recent Trends in Graphitic Carbon Nitride-Based Binary and Ternary Heterostructured Electrodes for Photoelectrochemical Water Splitting
}

\author{
Ravindranadh Koutavarapu 1 ${ }^{(}$, Shaik Gouse Peera 2 ${ }^{\circledR}$, Tae Gwan Lee ${ }^{2}$, Chimpiri Rao Myla ${ }^{3, *}$, Dong-Yeon Lee ${ }^{1, *}$, \\ Jaesool Shim ${ }^{4, *}$ and Suresh Kannan Balasingam ${ }^{5, *,+}$
}

1 Department of Robotics and Intelligent Machine Engineering, College of Mechanical and IT Engineering, Yeungnam University, Gyeongsan 712-749, Korea; ravindra_physicist@ynu.ac.kr

2 Department of Environmental Science and Engineering, Keimyung University, Daegu 42602, Korea; gouse@kmu.ac.kr (S.G.P.); wateree@naver.com (T.G.L.)

3 Department of Physics, Andhra Loyola College, Vijayawada 520-008, Andhra Pradesh, India

4 School of Mechanical Engineering, Yeungnam University, Gyeongsan 712-749, Korea

5 Department of Materials Science and Engineering, Faculty of Natural Sciences, Norwegian University of Science and Technology (NTNU), 7491 Trondheim, Norway

* Correspondence: raomc72@gmail.com (C.R.M.); dylee@ynu.ac.kr (D.-Y.L.); jshim@ynu.ac.kr (J.S.); suresh.k.balasingam@ntnu.no or suresh@korea.ac.kr (S.K.B.)

+ Current address: Graduate School of Energy and Environment (KU-KIST Green School), Korea University (KU), Seoul 136-713, Korea.

check for

updates

Citation: Koutavarapu, R.; Peera, S.G.; Lee, T.G.; Myla, C.R.; Lee, D.-Y.; Shim, J.; Balasingam, S.K. Recent Trends in Graphitic Carbon Nitride-Based Binary and Ternary Heterostructured Electrodes for Photoelectrochemical Water Splitting. Processes 2021, 9, 1959. https:// doi.org/10.3390/pr9111959

Academic Editor: Bipro R. Dhar

Received: 1 September 2021

Accepted: 29 October 2021

Published: 2 November 2021

Publisher's Note: MDPI stays neutral with regard to jurisdictional claims in published maps and institutional affiliations.

Copyright: (C) 2021 by the authors. Licensee MDPI, Basel, Switzerland. This article is an open access article distributed under the terms and conditions of the Creative Commons Attribution (CC BY) license (https:/ / creativecommons.org/licenses/by/ $4.0 /)$.

\begin{abstract}
The graphitic carbon nitride $\left(\mathrm{g}-\mathrm{C}_{3} \mathrm{~N}_{4}\right)$ is a class of two-dimensional layered material. The ever-growing research on this fascinating material is due to its unique visible light absorption, surface, electrocatalytic, and other physicochemical properties that can be useful to different energy conversion and storage applications. Photoelectrochemical (PEC) water splitting reaction is one of the promising applications of $\mathrm{g}-\mathrm{C}_{3} \mathrm{~N}_{4}$, wherein it acts as a durable catalyst support material. Very recently, the construction of $\mathrm{g}-\mathrm{C}_{3} \mathrm{~N}_{4}$-based binary and ternary heterostructures exhibited superior PEC water splitting performance owing to its reduced reunion of $\mathrm{e}-/ \mathrm{h}+$ pairs and the fast transfer of charge carriers at the heterostructure interface. This review compiles the recent advances and challenges on $\mathrm{g}_{-} \mathrm{C}_{3} \mathrm{~N}_{4}$-based heterostructured photocatalysts for the PEC water splitting reaction. After an overview of the available literature, we presume that $\mathrm{g}-\mathrm{C}_{3} \mathrm{~N}_{4}$-based photocatalysts showed enhanced PEC water splitting performance. Therefore, it is believed that these materials have tremendous opportunities to act as durable catalyst support for energy-related applications. However, researchers also considered several limitations and challenges for using $\mathrm{C}_{3} \mathrm{~N}_{4}$ as an efficient catalyst support material that must be addressed. This review article provides an overview of the fundamental principles of PEC water splitting, the current PEC water splitting research trends on $\mathrm{g}-\mathrm{C}_{3} \mathrm{~N}_{4}$-based binary and ternary heterostructured electrodes with respect to different electrolytes, and the other key factors influencing their photoelectrochemical performance. Finally, the future research direction with several recommendations to improve the photocatalytic efficiency of these materials is also provided at the end.
\end{abstract}

Keywords: $\mathrm{g}-\mathrm{C}_{3} \mathrm{~N}_{4}$; binary and ternary heterostructures; photoelectrochemical water splitting; hydrogen; photocatalyst

\section{Introduction}

With the rapid industrial developments and the expanding global population, the energy demand is constantly increasing, which has posed a significant threat to human life [1,2]. Furthermore, the extensive use of fossil fuels and industrial waste has led to a tremendous increase of greenhouse gases in the atmosphere [3,4]. On the other hand, renewable energy technologies such as wind, solar, and tidal energy have great potential 
for future generations [5]. Among these, solar energy is considered the most promising one, due to its earth abundance and non-hazardous nature [6]. However, the wavelength of solar illumination reaching the earth is greater than $340 \mathrm{~nm}$, containing only a small portion of UV light $(<3 \%)$ and a large amount of visible light in the range of $400-800 \mathrm{~nm}$. Therefore, the design and synthesis of suitable visible-light active semiconductor materials having a small bandgap are essential to harvest the abundant solar energy for photocatalytic and other renewable energy-related applications [6,7].

Hydrogen is an attractive green fuel that can be used for many different applications, such as heating, driving vehicles, and material refining [8,9]. Hydrogen has the potential to replace fossil fuels due to its highest energy density and the possibility to use in internal combustion engines and fuel cells, which will be the future for emission-free transportation [10-12]. Moreover, different water splitting techniques have been introduced for hydrogen production, such as electrochemical, thermochemical, photocatalytic, photoelectrochemical (PEC), and biological hydrogen production [13,14]. Among them, PEC water splitting is one of the ways to utilize solar energy for hydrogen generation, which can be further used for many other energy-related applications. $[15,16]$. Nevertheless, hydrogen production via PEC water splitting is one of the promising methods due to its safety factors, non-toxicity, and the final reaction that produces pure hydrogen and oxygen without any byproducts $[17,18]$.

\subsection{Fundamental Concepts of Semiconductor-Mediated Heterogeneous Photocatalysis}

Semiconductor-based nanostructures have received significant attention in recent years for energy and environmental applications due to their cost-effective and straightforward synthesis process, and mainly they have nanograins of different sizes and different kinds of heterostructured materials $[19,20]$. Further, the pristine semiconductor photocatalysts have exhibited minimal PEC water splitting abilities due to their rapid reunion of charge carriers and having a lower surface area [21,22]. Thus, a combination of various semiconductor materials with different morphologies can increase the performance in the visible-light range of the solar spectrum. Moreover, the coupled heterostructured materials with two or more components should have different energy levels that can play an essential role in the interfacial charge transfer of the electron $\left(\mathrm{e}^{-}\right)$and holes $\left(\mathrm{h}^{+}\right)$for the reduction and oxidation of water molecules on the surface of heterostructured electrodes to achieve a higher PEC water splitting activity [23,24].

In recent years, the graphitic carbon nitride $\left(\mathrm{g}-\mathrm{C}_{3} \mathrm{~N}_{4}\right)$ semiconductor-based binary and ternary heterostructured materials have acted as promising photocatalysts for the PEC water splitting and photocatalytic pollutant removal applications [25-27]. Therefore, several investigations have been done on $\mathrm{g}^{-} \mathrm{C}_{3} \mathrm{~N}_{4}$-based heterostructured photocatalysts for the PEC water splitting application. Moreover, the heterostructured electrodes are found as an attractive candidate due to their enhanced properties (such as larger surface area, active reactive sites, and higher light absorption capacity) when compared to their bulk counterparts [28,29]. In the case of a g- $\mathrm{C}_{3} \mathrm{~N}_{4}$-based heterostructured electrode, the suitable band edge potentials of the conduction band (CB) and valence band (VB) of different nanostructured semiconductor materials with various morphologies are combined with $\mathrm{g}^{-} \mathrm{C}_{3} \mathrm{~N}_{4}$, which could facilitate the charge transfer kinetics of photogenerated $\mathrm{e}^{-} / \mathrm{h}^{+}$ through the interfacial contact. Moreover, the solar-light active nanostructured materials upon the irradiation generate reactive oxygen species, and it also assists in suppressing the recombination rate of photogenerated $\mathrm{e}^{-} / \mathrm{h}^{+}$pairs $[30,31]$. Therefore, in heterostructured photocatalysts, the assembly of heterojunction could improve the photocatalytic reactions due to its extended absorption of light, synergistic interactions with facile charge transportation, and the reduced recombination rate of charge carriers [32,33].

\subsection{The Graphitic Carbon Nitride $\left(g-C_{3} N_{4}\right)$ Material}

The g- $\mathrm{C}_{3} \mathrm{~N}_{4}$ is a kind of strong allotrope of carbon nitride family having a bandgap of around $2.7 \mathrm{eV}$, and typically it is in the form of two-dimensional (2D) nanosheets comprising 
of tri-s-triazines interlayers [34]. The g- $\mathrm{C}_{3} \mathrm{~N}_{4}$ is one of the graphite-like layered structure materials (shown in Figure 1) with superior prospects due to their ease of availability, low price, and environmental friendliness [35].

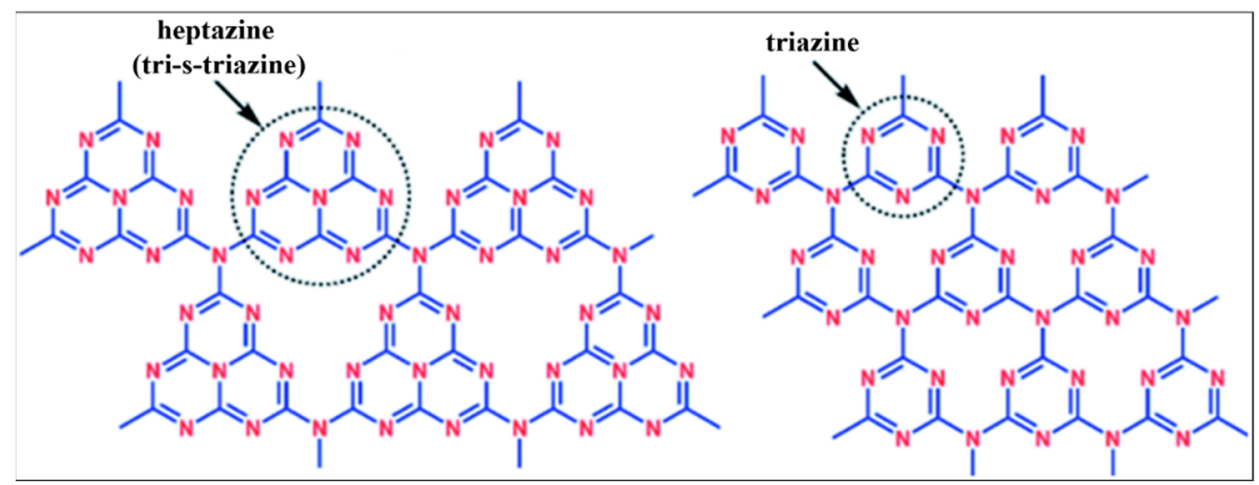

Figure 1. Two fundamental structural units of $\mathrm{g}-\mathrm{C}_{3} \mathrm{~N}_{4}$. Reprinted with permission from reference [36], Copyright 2018, Royal Society of Chemistry.

The g- $\mathrm{C}_{3} \mathrm{~N}_{4}$ molecular surface contains a large number of $\pi$-conjugated planar layers, which have an excellent complexing effect with high stability, so the material has been used for photocatalytic and PEC applications in recent years [37]. However, because of the utilization of only visible light, fast recombination of $\mathrm{e}^{-} / \mathrm{h}^{+}$pairs, low charge separation efficiency, and the moderate specific surface area, it can provide fewer active sites, which reduces its effective usage as a pristine photocatalyst [38,39]. Thus, in order to avoid these disadvantages, the design and synthesis of g- $\mathrm{C}_{3} \mathrm{~N}_{4}$-based semiconductor heterostructures with appropriate photocatalytic properties could be an effective approach for enhancing the PEC water splitting efficiency $[40,41]$.

\subsection{Basic Principles of PEC Water Splitting}

The increased accumulation of greenhouse gases has resulted in a constant increase in the global average temperature, enabling a shift in perspective and redirecting the focus from carbon-based energy resources to carbon-free renewable energy technologies [42,43]. In this context, PEC water splitting has foremost importance, in that it generates only $\mathrm{H}_{2}$ and $\mathrm{O}_{2}$ at two electrodes without any other polluting gases $[5,44]$. The schematic representation of the PEC water splitting mechanism is presented in Figure 2.

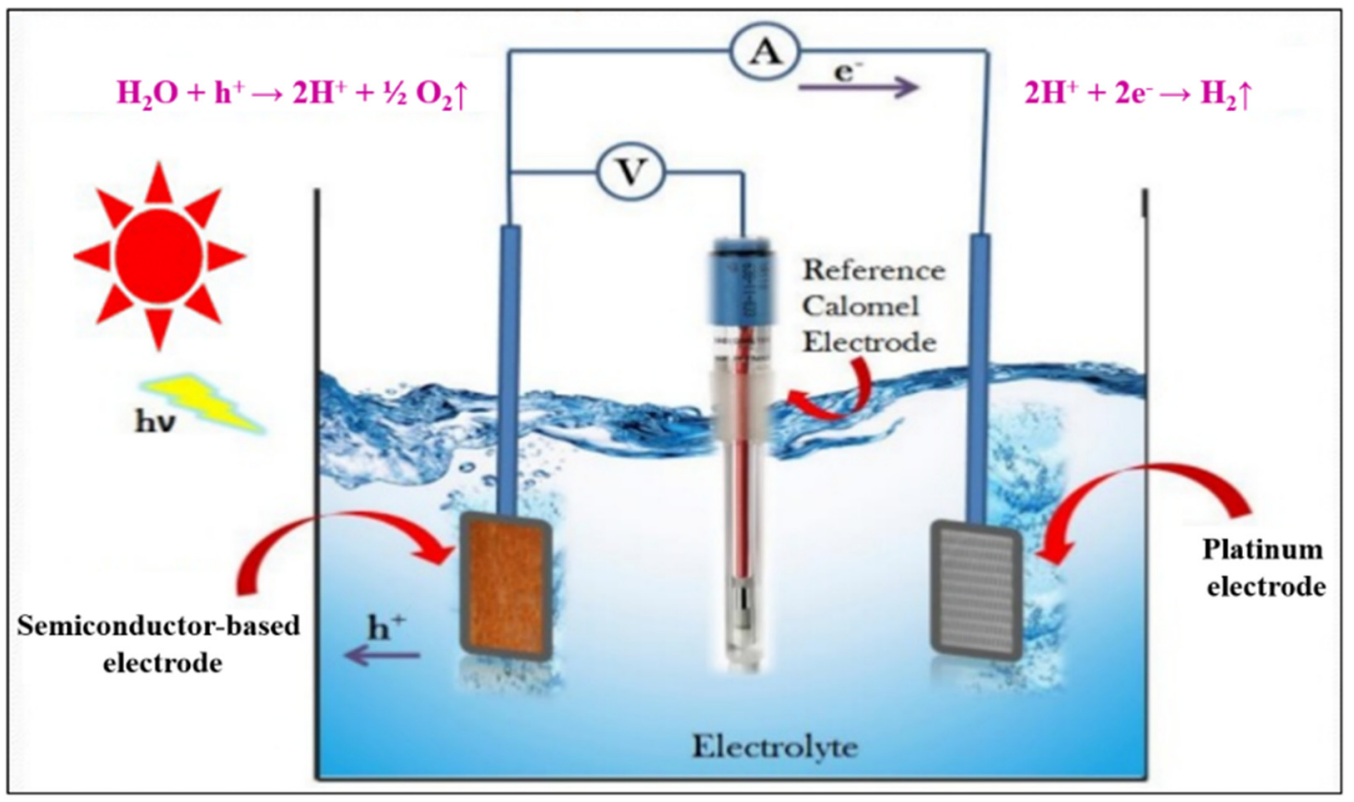

Figure 2. Schematic representation of PEC water splitting mechanism. 
Moreover, the PEC-based experiments are performed at room temperature, and the semiconductor electrodes are fabricated using inorganic compounds, which are stable in aqueous electrolytes. In contrast, organic-based semiconductor electrodes show poor stability in PEC water splitting reactions [45,46]. The PEC water splitting device employs quantum solar energy conversion materials in which the semiconductor absorbs incoming photons, resulting in the electron-hole pairs generation process. The incident sunlight on the photoanode excites electrons from the valence band to the conduction band, leaving behind holes in the valence band of semiconductor material [47]. Further, the charge separation typically occurs by the migration of carriers under the influence of the electric field, and the charge transfer occurs at the semiconductor/electrolyte interface. In a photoelectrode, the minority carriers are transported to the electrochemical interface in order to drive the reaction. For a photoanode, holes oxidize water molecules, and for a photocathode, electrons reduce the $\mathrm{H}^{+}$ions at the electrode surface [48].

For the past few years, solar-driven visible-light active semiconductor materials were combined with $\mathrm{g}-\mathrm{C}_{3} \mathrm{~N}_{4}$, which showed a better PEC water splitting performance due to their enhanced light absorption ability, robust synergistic interface, the enlarged surface area, and the effective separation of $\mathrm{e}^{-} / \mathrm{h}^{+}$pairs [49]. Furthermore, these $g-\mathrm{C}_{3} \mathrm{~N}_{4}$-based binary and ternary heterostructured electrodes with various morphologies can significantly progress the movement of charge carriers at the electrode/electrolyte interface and, in turn, enhance the PEC water splitting efficiency. However, despite these recent signs of progress, critical reviews on $\mathrm{g}-\mathrm{C}_{3} \mathrm{~N}_{4}$-based binary and ternary heterostructured photoelectrodes for the PEC water splitting reaction are still lacking. Therefore, this review summarizes the different types of $\mathrm{g}-\mathrm{C}_{3} \mathrm{~N}_{4}$-based binary and ternary heterostructured photoelectrodes used for PEC water splitting reaction, along with their advantages and limitations.

\section{Importance of g- $\mathrm{C}_{3} \mathrm{~N}_{4}$-Based Hybrid Heterostructured Electrodes}

Generally, when the pristine $\mathrm{g}-\mathrm{C}_{3} \mathrm{~N}_{4}$ is subjected to light, it absorbs photons and subsequently generates the photo-induced $\mathrm{e}^{-} / \mathrm{h}^{+}$pairs. However, the excited electrons in the $\mathrm{CB}$ are in a most unstable state and will tend to occupy the stable state, thus coming back to the VB and recombining with photogenerated holes [50]. Therefore, to suppress the recombination of charge carriers and achieve maximum efficiency, $g-\mathrm{C}_{3} \mathrm{~N}_{4}$ should combine with other semiconductor photocatalysts through the formation of heterostructured electrodes [51]. Recently, some approaches have been introduced to enhance the solar-driven visible-light active photocatalytic performance of $\mathrm{g}-\mathrm{C}_{3} \mathrm{~N}_{4}$ materials. For instance, the construction of heterostructured electrodes with $\mathrm{g}-\mathrm{C}_{3} \mathrm{~N}_{4}$ and other semiconductors, doping with metals and non-metals, and the fabrication of mesoporous heterostructures [52-54]. Among them, the construction of $\mathrm{g}-\mathrm{C}_{3} \mathrm{~N}_{4}$-based binary and ternary heterostructured electrodes exhibited a superior PEC activity due to its reduced reunion of electron-hole pairs and the quick transfer of charge carriers at the interface of the heterostructured electrodes. Furthermore, while developing g- $\mathrm{C}_{3} \mathrm{~N}_{4}$-based heterostructured electrodes, $\mathrm{g}-\mathrm{C}_{3} \mathrm{~N}_{4}$ should associate with both the visible and UV light-based semiconductor materials, which could enlarge the absorption of the solar spectrum to the maximum range [55,56].

\section{3. g- $\mathrm{C}_{3} \mathrm{~N}_{4}$-Based Binary Heterostructured Photoelectrodes for PEC Water Splitting}

The pristine $\mathrm{g}-\mathrm{C}_{3} \mathrm{~N}_{4}$ material has limitations such as fast $\mathrm{e}^{-} / \mathrm{h}^{+}$reunion rate, restricted to visible-light absorption range, and the moderate surface area, which urges the development of new approaches to enhance its applications $[57,58]$. To overcome the above limitations and achieve greater efficiencies, $\mathrm{g}-\mathrm{C}_{3} \mathrm{~N}_{4}$-based binary heterostructures have been constructed, and some of them are reported here. Binary heterostructures of $g-C_{3} \mathrm{~N}_{4}$, along with various concentrations of $\operatorname{MnO}_{x}(2,5,7,10$, and 15\%), were synthesized via in-situ thermal decomposition method to enhance the PEC activity [59]. The XRD result showed that the hexagonal phase of $\mathrm{g}-\mathrm{C}_{3} \mathrm{~N}_{4}$, the monoclinic phase of $\mathrm{MnO}_{\mathrm{x}}$, and the heterostructure formation did not affect the individual components. The morphology results established that the irregular-shaped $\mathrm{MnO}_{\mathrm{x}}$ nanoparticles (NPs) dispersed over the 
g- $\mathrm{C}_{3} \mathrm{~N}_{4}$ surface. The visible-light-harvesting ability of an electrode was enhanced by the formation of heterostructure when compared to pristine samples. From the electrochemical impedance spectroscopy (EIS) results, the $10 \% \mathrm{MnO}_{\mathrm{x}} / \mathrm{g}-\mathrm{C}_{3} \mathrm{~N}_{4}$ heterostructured electrode exhibited the lowest charge transfer resistance $\left(R_{c t}\right)$ compared to the remaining samples. Further, the $10 \% \mathrm{MnO}_{\mathrm{x}} / \mathrm{g}-\mathrm{C}_{3} \mathrm{~N}_{4}$ heterostructured electrode showed a higher photocurrent density $\left(0.003 \mathrm{~A} \mathrm{~cm}^{-2}\right.$ at $1.25 \mathrm{~V}$ vs. $\left.\mathrm{Ag} / \mathrm{AgCl}\right)$ than the remaining photoanodes. Thus, the synergistic interactions among $\mathrm{g}-\mathrm{C}_{3} \mathrm{~N}_{4}$ and $\mathrm{MnO}_{\mathrm{x}}$ can effectively progress the mobility of charge carriers and diminish the reunion of $\mathrm{e}^{-} / \mathrm{h}^{+}$pairs, which enhances the PEC performance. Wang et al. successfully constructed a core-shell g- $\mathrm{C}_{3} \mathrm{~N}_{4} @ Z \mathrm{ZnO}(\mathrm{CN} / \mathrm{ZN})$ heterostructured electrode with different amounts of $g-\mathrm{C}_{3} \mathrm{~N}_{4}(0.01,0.05,0.10,0.15,0.20 \mathrm{~g}) \mathrm{using}$ a facile reflux technique [60]. The XRD results (Figure 3a) confirmed the hexagonal phase of $\mathrm{ZnO}$ and the interlayer stacking of $\mathrm{CN}$ units with no impurity phases. The morphology studies (Figure 3b) showed the heterostructure formation with an effective distribution of $\mathrm{ZnO}$ NPs over the $\mathrm{CN}$ surface. When compared to the pristine $\mathrm{ZnO}$, the visible-light absorption ability of the $\mathrm{CN} / \mathrm{ZN}$ heterostructured electrode (Figure 3c) is enhanced through the formation of heterostructures. The EIS results (Figure $3 \mathrm{~d}$ ) demonstrated that the $\mathrm{CN} / \mathrm{ZN}$ 0.15 heterostructured electrode exhibited the lowest charge-transfer resistance $\left(\mathrm{R}_{\mathrm{ct}}\right)$ among all samples. From the transient photocurrent (I-t) results (Figure 3e), the CN/ZN-0.15 photoelectrode exhibited a sharp increase of photocurrent density with a quick photoresponse than the other samples. Furthermore, the $\mathrm{CN} / \mathrm{ZN}-0.15$ photoelectrode provided a highest photocurrent density at $1.5 \mathrm{~V}$ vs. SCE in $0.1 \mathrm{M} \mathrm{Na}_{2} \mathrm{SO}_{4}$ electrolyte under visible-light illumination. This improvement in the PEC water splitting activity (Figure 3f) is owed to the core-shell morphology, higher light absorption capability, formation of synergistic interfaces, and the facile charge carrier transport.

Xiao et al. successfully constructed a binary heterostructured electrode in which zerodimensional (0D) $\mathrm{g}-\mathrm{C}_{3} \mathrm{~N}_{4}$ NPs covered over the one-dimensional (1D) $\mathrm{TiO}_{2}$ nanotube arrays with an interfacial oxygen vacancy layer (CN/OV-TO). This heterostructured electrode was synthesized using anodic oxidation followed by the reduction and vapor deposition processes [61]. The visible-light-harvesting ability is improved substantially after forming the heterostructure and oxygen vacancies (OV) associated with $\mathrm{CN}, \mathrm{TO}$, and $\mathrm{CN} / \mathrm{TO}$. The structural and morphology investigations confirmed the formation of 0D/1D heterostructured electrodes. Further, the EIS results demonstrated that the constructed CN/OV-TO heterostructured electrode exhibited the smallest $\mathrm{R}_{\mathrm{ct}}$ value among all prepared samples. In addition, the photocurrent density of CN/OV-TO photoanode is around $0.72 \mathrm{~mA} \mathrm{~cm}^{-2}$ at $1.23 \mathrm{~V}$ Vs. RHE under visible-light illumination. This value is almost eight times higher than the CN/TO heterostructured electrode without an interfacial OV layer. This enhanced water splitting ability was attributed to the Z-scheme mechanism along with the interfacial OV layer, which delays the reunion of $\mathrm{e}^{-} / \mathrm{h}^{+}$pairs and endorses the facile charge carrier transport mechanism. Reddy et al. constructed $1 \mathrm{D} \mathrm{ZnWO}_{4}$ nanorods decorated over the $2 \mathrm{D} \mathrm{g}-\mathrm{C}_{3} \mathrm{~N}_{4}$ nanosheets using a facile hydrothermal synthesis method to enhance the PEC water splitting reaction under solar light [62]. By the formation of the heterostructured electrode, the solar light-harvesting capability was remarkably improved. The crystal phase and morphology analysis confirmed the formation of the heterostructured electrode by the successful decoration of $\mathrm{ZnWO}_{4}$ nanorods on the surface of $\mathrm{g}-\mathrm{C}_{3} \mathrm{~N}_{4}$ nanosheets. Further, the EIS results validated that the constructed $2 \mathrm{D} / 1 \mathrm{D}$ heterostructured electrodes exhibited the lowest $R_{c t}$ value when compared to pristine samples. Moreover, the photocurrent density of the 2D/1D heterostructured electrode is almost 6.75 times and 3.31 times higher than the pristine $\mathrm{ZnWO}_{4}$ and $\mathrm{g}-\mathrm{C}_{3} \mathrm{~N}_{4}$ electrodes, respectively. Nevertheless, the 2D/1D heterostructured electrode exhibited a very good stability and thus the formation of a binary heterostructured electrode could effectively improve the migration of charge carriers with a lower charge transfer resistance and suppress the reunion of $\mathrm{e}^{-} / \mathrm{h}^{+}$charge carriers. 

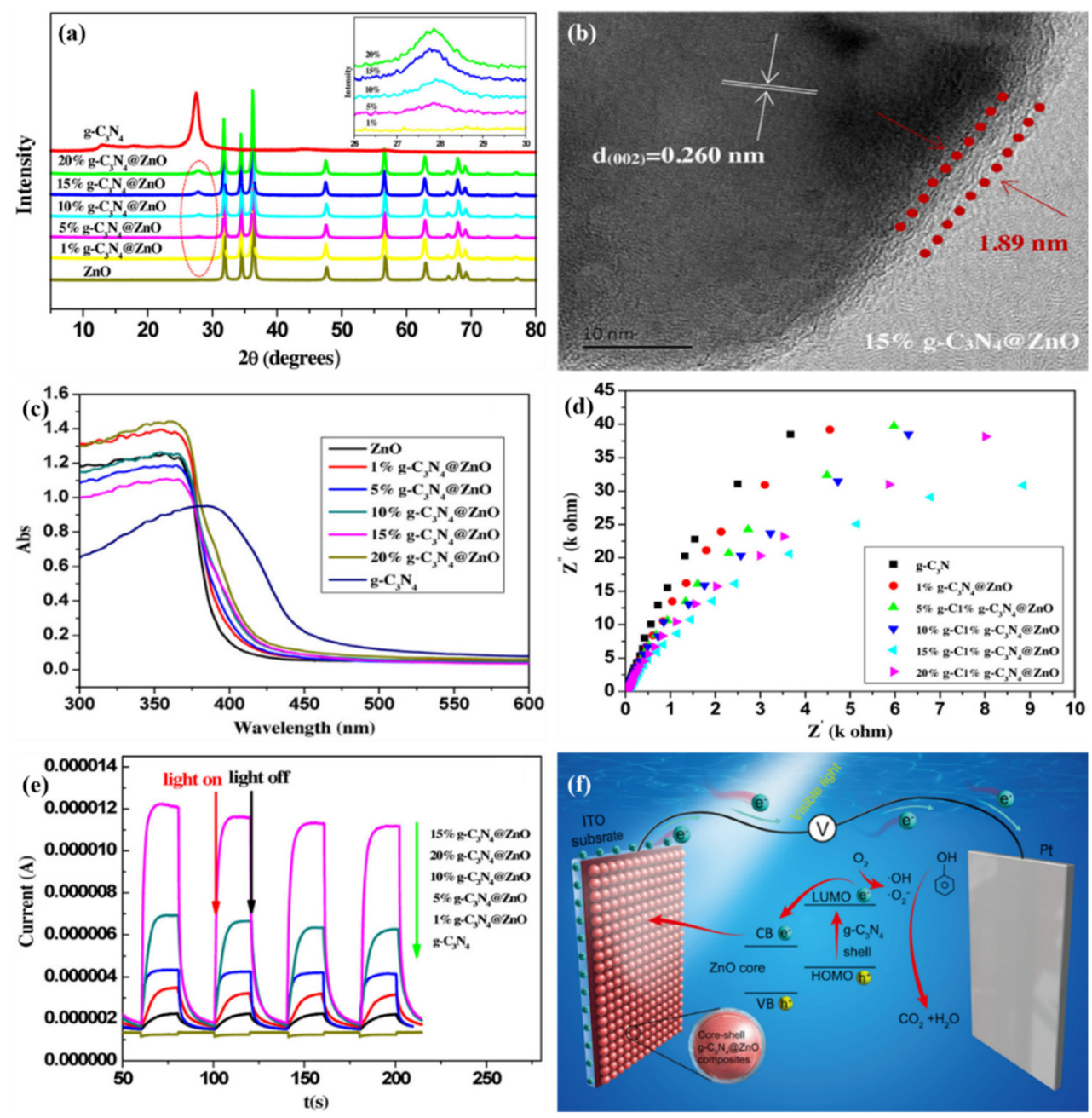

Figure 3. (a) XRD patterns, (b) HRTEM image of 15\%CN@ZO material, (c) optical absorption spectra, (d) Nyquist plots, (e) I-t curves, and (f) charge transfer mechanism of the CN@ZO heterostructured electrode. Reprinted with permission from reference [60], Copyright 2017, Elsevier.

A novel hybrid carbon-doped $\mathrm{CuO} / \mathrm{g}-\mathrm{C}_{3} \mathrm{~N}_{4}(\mathrm{C}-\mathrm{CuO} / \mathrm{CN})$ heterostructured electrode was prepared using a facile one-step microwave-supported approach to improve the PEC performance under visible source [40]. The crystal phase results confirmed the formation of the monoclinic phase of $\mathrm{CuO}$ and the interlayer stacking of the $\mathrm{CN}$ units. The morphology results demonstrated that the $\mathrm{CuO}$ seems to be an evenly dispersed micro-flowers consisting of intermixed ultrathin nanosheets and distributed over the surface of $\mathrm{CN}$. The photoluminescence spectra of $\mathrm{C}-\mathrm{CuO} / \mathrm{CN}$ heterostructured material showed a very weak intensity compared to the $\mathrm{CuO}, \mathrm{CN}$, and $\mathrm{CuO} / \mathrm{CN}$ materials, and this enhanced PL activity can be ascribed to the significance of carbon dopant, which influences lattice defects. The $\mathrm{C}-\mathrm{CuO} / \mathrm{CN}$ heterostructured electrode exhibited the lowest charge transfer resistance of $3.48 \mathrm{k} \Omega \mathrm{cm}^{-2}$ than the $\mathrm{CuO}\left(18.53 \mathrm{k} \Omega \mathrm{cm}^{-2}\right)$ and $\mathrm{CuO} / \mathrm{CN}$ $\left(7.69 \mathrm{k} \Omega \mathrm{cm}^{-2}\right)$ electrodes. Furthermore, the photocurrent density of the $\mathrm{C}-\mathrm{CuO} / \mathrm{CN}$ electrode is around $-2.85 \mathrm{~mA} \mathrm{~cm}^{-2}$ at $0 \mathrm{~V}$ vs. RHE under visible source, and it is around $227 \%$ and $38 \%$ higher than the $\mathrm{CuO}$ and $\mathrm{CuO} / \mathrm{CN}$ electrodes, respectively. Thus, the carbon-doping, influence of lattice defects, and the formation of interfacial interactions significantly enhanced the PEC performance.

Seza and co-workers successfully constructed novel photoelectrodes made of $\mathrm{SnO}_{2}$ NPs (various loading of $0.175,0.6$, and $1 \mathrm{~g}$ ) decorated over the surface of porous g- $\mathrm{C}_{3} \mathrm{~N}_{4}$ nanosheets $(\mathrm{CN} / \mathrm{SN})$ using a facile microwave synthesis method [63]. The XRD results demonstrated that the $\mathrm{CN} / \mathrm{SN}$ heterostructured material exhibited both the g- $\mathrm{C}_{3} \mathrm{~N}_{4}$ 
and $\mathrm{SnO}_{2}$ phases. The morphology results showed the highly porous structure of $\mathrm{CN}$ nanosheets and the irregular shape of $\mathrm{SnO}_{2}$ NPs. The light absorption capacity of heterostructured $\mathrm{CN} / \mathrm{SN}$ electrode enhanced towards the visible-active region compared to the pristine samples. The CN/SN-0.175 heterostructured electrode exhibited the highest specific surface area of $195 \mathrm{~m}^{2} \mathrm{~g}^{-1}$ compared to the other samples. From the linear sweep voltammetry (LSV) results, the CN/SN-0.175 heterostructured electrode showed a photocurrent density of $0.033 \mathrm{~mA} \mathrm{~cm}^{-2}$ at $1.2 \mathrm{~V}$ vs. $\mathrm{Ag} / \mathrm{AgCl}$ in $0.2 \mathrm{M} \mathrm{Na}_{2} \mathrm{SO}_{4}$ electrolyte under visible-light irradiation, and this photocurrent value is superior to the remaining photoelectrodes. This enhanced PEC performance can be ascribed to the formation of porous nanosheets, enhanced visible-light absorption ability, and the formation of the interfacial heterostructure.

Novel binary g- $\mathrm{C}_{3} \mathrm{~N}_{4}$ combined with carbon nanotubes ( $\mathrm{CN} / \mathrm{CT}$ ) heterostructured film was systematically fabricated on the FTO substrate using a facile polycondensation method to enhance PEC water splitting ability [52]. The structural and morphological analysis evidence the formation of CN/CT heterostructured electrodes with synergistic interfaces. As a result, the light-harvesting capacity systematically improved towards the visible-active region by the development of heterostructure. Further, the EIS results validated that the constructed $\mathrm{CN} / \mathrm{CT}$ heterostructured electrode showed the lowest charge transfer resistance of $6.5 \times 10^{5} \Omega$, and it is around 9.3 times higher than the pristine $\mathrm{CN}$ electrode. The photocurrent density of the CN/CT heterostructured electrode showed $0.075 \mathrm{~mA} \mathrm{~cm}^{-2}$ at $1 \mathrm{~V}$ vs. $\mathrm{Ag} / \mathrm{AgCl}$ under visible light, and it is around 11 times superior to the pure $\mathrm{CN}$ photoanode. Thus, combing CN with CT significantly enhanced the electron conductivity, light-harvesting ability, and the separation of charge carriers, which further improved the PEC water splitting efficiency. Bakr and co-workers successfully constructed a binary Z-scheme heterostructured electrode using $\alpha-\mathrm{Fe}_{2} \mathrm{O}_{3}$ nanotubes combined with various concentrations $\left(1,2\right.$, and $3.75 \mathrm{wt}$.\%) of ruptured tubular $\mathrm{g}-\mathrm{C}_{3} \mathrm{~N}_{4}(\mathrm{FO} / \mathrm{CN})$ using an electrostatic self-assembly technique [64]. The XRD results revealed that both crystal phases were presented in the FO/CN heterostructured electrode. The morphology results showed that the $\alpha-\mathrm{Fe}_{2} \mathrm{O}_{3}$ nanotubes were anchored over the tubular $\mathrm{g}-\mathrm{C}_{3} \mathrm{~N}_{4}$, and the bandgap modification was detected for the FO/CN heterostructured material. The EIS results exhibited the lowest charge transfer resistance value for FO/CN-1 sample. Furthermore, the FO/CN1 heterostructured electrode showed the highest photocurrent density of $0.0055 \mathrm{~mA} \mathrm{~cm}^{-2}$ at $1 \mathrm{~V}$ vs. SCE in $0.1 \mathrm{M} \mathrm{Na}_{2} \mathrm{SO}_{4}$ electrolyte under sunlight. This improvement in the PEC performance was due to the morphological interfaces, heterostructure formation, and quick transportation of charge carriers.

Novel binary heterostructured electrodes made of $\mathrm{BiOI}$ nanoplates combined with multilayered $g-\mathrm{C}_{3} \mathrm{~N}_{4}(\mathrm{BI} / \mathrm{CN}-\mathrm{M})$ and few-layered $\mathrm{g}-\mathrm{C}_{3} \mathrm{~N}_{4}$ nanosheets (BI/CN-S) were systematically synthesized using a simple solvothermal technique for the enhancement of PEC water splitting reaction [65]. The XRD results showed the formation of the tetragonal phase of $\mathrm{BiOI}$ and the interlayer stacking of $\mathrm{CN}$, and both crystal phases have appeared in the BI/CN-S heterostructured electrode. The morphology results demonstrated that the BI nanoplates were decorated over the CN-S nanosheets, which confirmed the establishment of the heterostructured material. Further, the FTIR and Raman spectra results evidently showed the synergistic interactions among BI and CN materials. From the EIS results, the $\mathrm{BI} / \mathrm{CN}-\mathrm{S}$ heterostructured electrode showed the lowest charge transfer resistance than the pure BI, CN, and BI/CN-M electrodes. Moreover, the observed photocurrent density of $\mathrm{BI} / \mathrm{CN}-\mathrm{S}$ heterostructured electrode was around $0.20 \mathrm{~mA} \mathrm{~cm}^{-2}$ at $-0.5 \mathrm{~V}$ vs. $\mathrm{Ag} / \mathrm{AgCl}$ in $0.1 \mathrm{M} \mathrm{Na}_{2} \mathrm{SO}_{4}$ under visible-light irradiation, and the current density value was superior to BI/CN-M (0.16 mA cm $\left.{ }^{-2}\right)$, BI $\left(0.09 \mathrm{~mA} \mathrm{~cm}^{-2}\right), \mathrm{CN}-\mathrm{M}\left(0.05 \mathrm{~mA} \mathrm{~cm}^{-2}\right)$, and CN-S $\left(0.04 \mathrm{~mA} \mathrm{~cm}^{-2}\right)$ electrodes. The enhanced water-splitting ability of the heterostructure material was attributed to the enlarged light absorption ability, the diminished reunion of charge carriers, and the synergistic trap passivation in the heterostructured electrode.

Liu and colleagues constructed the well-designed $\mathrm{TiO}_{2}$ nanotube arrays (TNTAs) and dispersed the $\mathrm{g}-\mathrm{C}_{3} \mathrm{~N}_{4}$ nanoparticles over TNTAs using anodic oxidation followed by calci- 
nation methods [66]. The formation mechanism of g- $\mathrm{C}_{3} \mathrm{~N}_{4} / \mathrm{TNTAs}(\mathrm{CN}-\mathrm{TN})$ heterojunction was schematically represented in Figure $4 \mathrm{a}$. The crystallographic results showed the anatase phase of $\mathrm{TiO}_{2}$ and interlayer stacking of $\mathrm{g}-\mathrm{C}_{3} \mathrm{~N}_{4}$, which significantly confirmed the formation of heterojunctions. The morphology results from Figure $4 \mathrm{~b}-\mathrm{d}$ showed that the $\mathrm{g}-\mathrm{C}_{3} \mathrm{~N}_{4}$ nanosheets covered the walls of the $\mathrm{TiO}_{2}$ nanotubes. From the LSV results (Figure 4e), the photocurrent density of CN-TN electrode was observed around $0.86 \mathrm{~mA} \mathrm{~cm}^{-2}$ and is nearly double that of pure TNTAs electrode. The transient photocurrent (I-t) results (Figure 4f) demonstrated that the $\mathrm{CN}-\mathrm{TN}$ heterojunction electrode exhibited a sharp increase of photocurrent density with a quick photoresponse compared to the as-prepared pristine samples. The charge transfer resistance of the $\mathrm{CN}-\mathrm{TN}$ heterojunction electrode (Figure $4 \mathrm{~g}$ ) was significantly reduced among the other samples under light illumination. Thus, the formation of binary heterojunction between $\mathrm{g}-\mathrm{C}_{3} \mathrm{~N}_{4}$ and TNTAs (Figure $4 \mathrm{~h}$ ) could significantly enhance the transportation of charge carriers and reduce the reunion of photo-induced $\mathrm{e}^{-} / \mathrm{h}^{+}$pairs, which in turn enhanced the PEC water splitting efficiency.
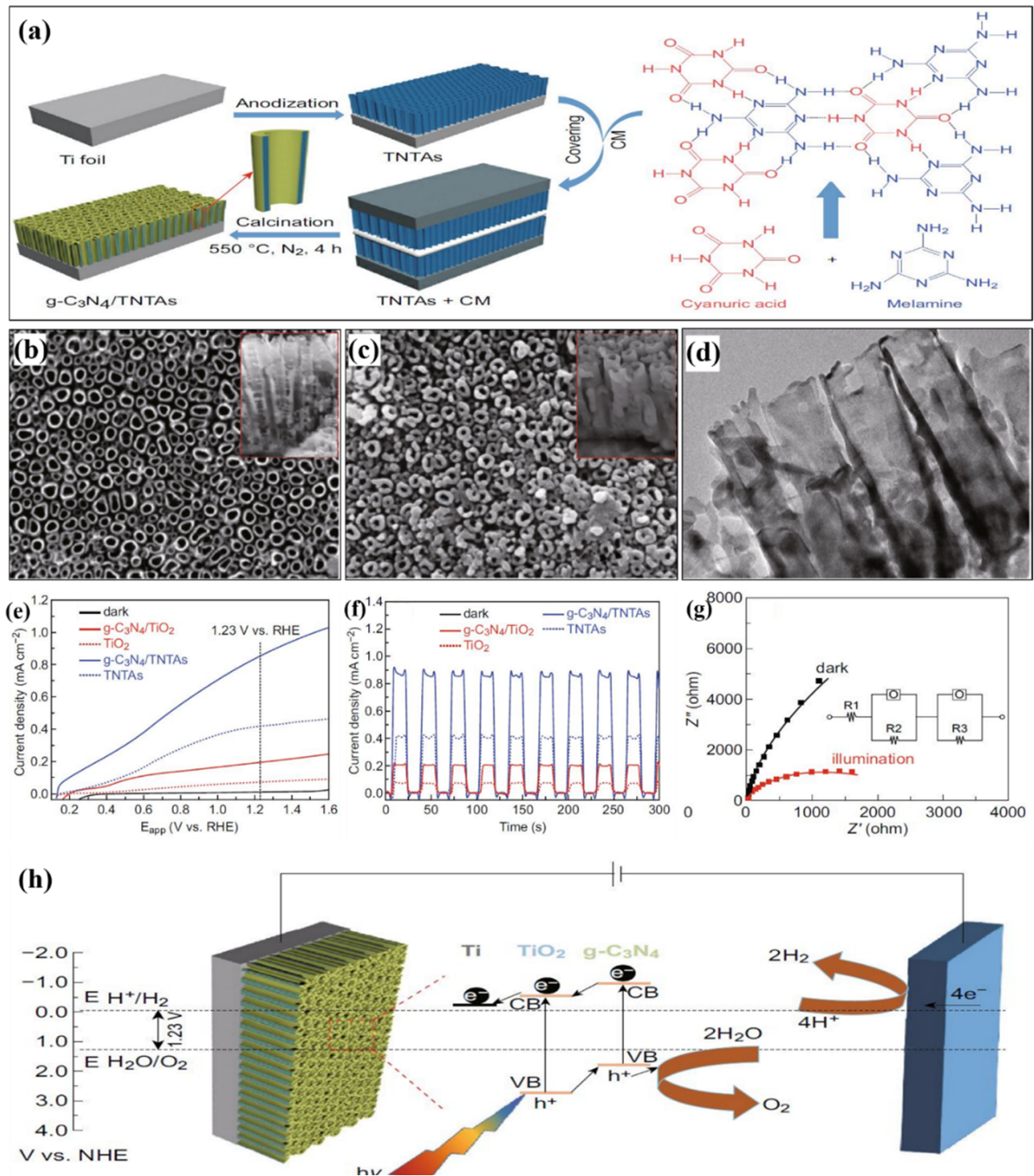

Figure 4. (a) Formation mechanism of CN-TN heterojunction, SEM images of (b) TNTAs, (c) CN-TN heterojunction, (d) TEM image of CN-TN heterojunction, (e) LSV curves, (f) $I-t$ curves, (g) Nyquist plots, and (h) charge transfer mechanism of the CN-TN heterojunction. Reprinted with permission from reference [66], Copyright 2018, Springer. 
Liu and co-workers effectively fabricated the g- $\mathrm{C}_{3} \mathrm{~N}_{4}$-coated $\mathrm{Fe}_{2} \mathrm{O}_{3}$ nanoplatelets (CN/FO) electrodes using the facile electrodeposition followed by chemical vapor deposition methods [67]. The morphology and structural results demonstrated the distribution of g- $\mathrm{C}_{3} \mathrm{~N}_{4}$ nanoparticles over the surface of $\mathrm{Fe}_{2} \mathrm{O}_{3}$ nanoplatelets. Further, the light-harvesting ability was significantly enhanced after the formation of $\mathrm{CN} / \mathrm{FO}$ heterostructuredelectrode, and the PL intensity was diminished when compared to the pure $\mathrm{CN}$ and FO electrodes. From the EIS analysis, the CN/FO heterostructured photoanode showed the lowest $R_{c t}$ value compared to the remaining photoanodes. The photocurrent density of the $\mathrm{CN} / \mathrm{FO}$ heterostructured electrode showed around $0.78 \mathrm{~mA} \mathrm{~cm}^{-2}$ at $0.4 \mathrm{~V}$ vs. $\mathrm{Ag} / \mathrm{AgCl}$ in $1.0 \mathrm{M}$ $\mathrm{NaOH}$ under visible light, and it is around 70 times higher than the pure FO photoanode. Therefore, the introduction of $\mathrm{CN}$ over the surface of $\mathrm{FO}$ considerably enriched the light-harvesting ability, separation of $\mathrm{e}^{-} / \mathrm{h}^{+}$pairs, and quicker interfacial charge transfer, which improved the water-splitting ability. Novel binary 2D/2D heterostructured electrode composed of porous $\mathrm{g}-\mathrm{C}_{3} \mathrm{~N}_{4}$ and $\mathrm{BCN}$ nanosheets $(\mathrm{CN} / \mathrm{BCN})$ was successfully fabricated using a facile thermal polymerization technique [68]. The $\mathrm{XRD}$ results demonstrated that both the crystal phases of $\mathrm{CN}$ and $\mathrm{BCN}$ were presented in the $\mathrm{CN} / \mathrm{BCN}$ heterostructured electrode. The morphology results showed that the porous $\mathrm{CN}$ nanosheets were anchored over the BCN nanosheets. From differential reflectance spectroscopy (DRS) results, the loading of $\mathrm{CN}$ towards $\mathrm{BCN}$ could substantially enhance the light-harvesting capability. The charge transfer resistance of $\mathrm{CN} / \mathrm{BCN}$ electrode was around $2.8 \mathrm{k} \Omega$, which is 11 times and five times lesser than $\mathrm{CN}$ and $\mathrm{BCN}$ electrodes, respectively. Further, the transient photocurrent density of the $\mathrm{CN} / \mathrm{BCN}$ electrode is higher than the individual $\mathrm{CN}$ and $\mathrm{BCN}$ electrodes. Moreover, the $\mathrm{CN} / \mathrm{BCN}$ heterostructured electrodes showed a photocurrent density of $0.62 \mathrm{~mA} \mathrm{~cm}^{-2}$ at $0.62 \mathrm{~V}$ vs. $\mathrm{Ag} / \mathrm{AgCl}$ in $0.1 \mathrm{M} \mathrm{Na}_{2} \mathrm{SO}_{4}$ electrolyte under visiblelight illumination, which was around 8 and 3 times higher than the $\mathrm{CN}\left(0.08 \mathrm{~mA} \mathrm{~cm}{ }^{-2}\right)$ and $\mathrm{BCN}\left(0.21 \mathrm{~mA} \mathrm{~cm}^{-2}\right)$ electrodes, respectively. Thus, the morphological 2D interfaces, superior migration of charge carriers, and the separation of $\mathrm{e}^{-} / \mathrm{h}^{+}$pairs significantly enhanced the PEC water splitting performance.

Murugan and colleagues systematically fabricated a binary g- $\mathrm{C}_{3} \mathrm{~N}_{4} / \mathrm{TiO}_{2}(\mathrm{CN} / \mathrm{TO})$ heterostructured electrode with different concentrations of $\mathrm{CN}(5,10,15,20$, and $25 \mathrm{wt} . \%)$ using a facile in-situ soft template technique (Figure 5a) for the improvement of PEC water splitting performance [69]. The XRD results (Figure 5b) confirmed the anatase phase of $\mathrm{TiO}_{2}$, the interlayer stacking of $\mathrm{CN}$, and both the phases have appeared in the CN/TO heterostructured electrode. The morphology results (Figure $5 \mathrm{c}, \mathrm{d}$ ) demonstrated that the TO NPs were decorated over the CN nanosheets. From the EIS analysis (Figure 5e), the CN/TO20 photoanode showed the lowest $R_{\mathrm{ct}}$ value than the remaining photoanodes. Furthermore, the photocurrent density (Figure $5 \mathrm{f}-\mathrm{g}$ ) of $\mathrm{CN} / \mathrm{TO}-20$ heterostructured electrode was around $0.0723 \mathrm{~mA} \mathrm{~cm}^{-2}$ at $1.23 \mathrm{~V}$ vs. RHE in $1 \mathrm{M} \mathrm{KOH}$ electrolyte under visible-light and the photocurrent density value was superior than the $\mathrm{CN}\left(0.00082 \mathrm{~mA} \mathrm{~cm}^{-2}\right), \mathrm{TO}(0.0366 \mathrm{~mA}$ $\left.\mathrm{cm}^{-2}\right), \mathrm{CN} / \mathrm{TO}-5\left(0.0472 \mathrm{~mA} \mathrm{~cm}^{-2}\right), \mathrm{CN} / \mathrm{TO}-10\left(0.0544 \mathrm{~mA} \mathrm{~cm}^{-2}\right), \mathrm{CN} / \mathrm{TO}-15(0.0632 \mathrm{~mA}$ $\left.\mathrm{cm}^{-2}\right)$, and $\mathrm{CN} / \mathrm{TO}-25\left(0.0658 \mathrm{~mA} \mathrm{~cm}{ }^{-2}\right)$ electrodes. The enhanced water splitting ability was accounted for their enlarged light absorption ability, the diminished reunion of charge carriers, and synergistic interfacial effect in the heterostructured electrode. The same group, Murugan and co-workers, successfully fabricated a binary combination of hierarchical $\mathrm{Bi}_{2} \mathrm{MoO}_{6}$ and various amounts $(1,3,5,7,10$, and $12 \mathrm{wt} . \%)$ of g- $\mathrm{C}_{3} \mathrm{~N}_{4}(\mathrm{BMO} / \mathrm{CN})$ using a solvothermal technique for the enhancement of PEC water splitting ability [70]. The XRD results revealed the formation of the orthorhombic phase of $\mathrm{BMO}$, the interlayer stacking of $\mathrm{CN}$, and both the phases have appeared in the $\mathrm{BMO} / \mathrm{CN}$ heterostructured electrode. The regulation of the bandgap was detected for the $\mathrm{BMO} / \mathrm{CN}$ heterostructured electrode compared to the pure samples, which enlarged the visible-light-harvesting capability. From the EIS analysis, the $\mathrm{BMO} / \mathrm{CN}-10$ heterostructured electrode showed the lowest $\mathrm{R}_{\mathrm{ct}}$ value, the photocurrent density of the $\mathrm{BMO} / \mathrm{CN}-10$ electrode was around $0.0212 \mathrm{~mA} \mathrm{~cm}{ }^{-2}$ at 1.23 $\mathrm{V}$ vs. RHE in $1 \mathrm{M} \mathrm{KOH}$ electrolyte under visible-light illumination, and the photocurrent density value was about 28 and 7 times greater than the pristine $\mathrm{CN}$ and $\mathrm{BMO}$ electrodes, 
respectively. Thus, heterostructure formation significantly enhanced the light-harvesting ability, separation of $\mathrm{e}^{-} / \mathrm{h}^{+}$pairs, and quicker interfacial charge transfer, which progressed the water-splitting ability.
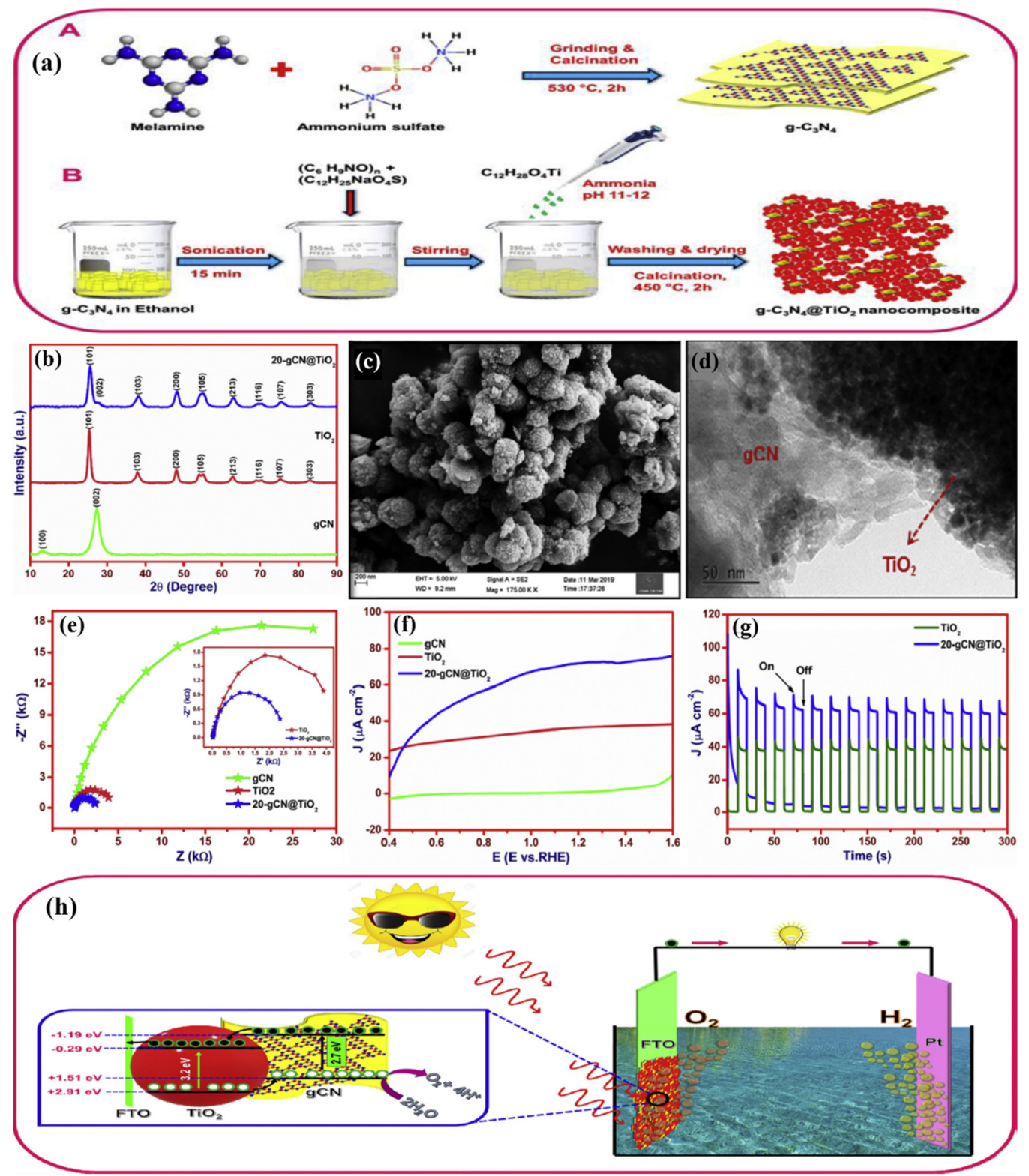

Figure 5. (a) Formation mechanism of CN@TO heterostructured material, (b) XRD patterns, (c) SEM image of 20-CN@TO material, (d) TEM image of 20-CN@TO material, (e) Nyquist plots, (f) LSV curves, (g) I-t curves, and (h) charge transfer mechanism of the CN@TO heterostructured electrodes. Reprinted with permission from reference [69], Copyright 2020, Elsevier.

Mohammad et al. successfully fabricated the novel heterostructured electrode using different concentrations ( 2 and $4 \mathrm{mM}$ ) of $\mathrm{SnO}_{2}$ NPs decorated over the surface of $\mathrm{g}-\mathrm{C}_{3} \mathrm{~N}_{4}$ nanosheets $(\mathrm{CN} / \mathrm{SN})$ via a simple hydrothermal method [71]. The XRD results confirmed that both the crystal phases of SN (tetragonal rutile phase) and CN were presented in the CN/SN heterostructured electrode without any impurity phases. The FTIR and XPS results established the formation of $\mathrm{CN} / \mathrm{SN}$ heterostructured electrodes. The visible-lightharvesting ability was significantly enhanced after forming the CN/SN heterostructured electrode, and the PL intensity was diminished compared to the pure CN and SN materials. The CN/SN-4 mM heterostructured electrode demonstrated a higher specific surface area 
of $181.54 \mathrm{~m}^{2} \mathrm{~g}^{-1}$ than the pure SN $\left(181.13 \mathrm{~m}^{2} \mathrm{~g}^{-1}\right)$ and CN/SN-2 mM $\left(178.69 \mathrm{~m}^{2} \mathrm{~g}^{-1}\right)$ electrodes. From the EIS results, the CN/SN-4 mM heterostructured electrode showed the lowest charge transfer resistance when compared to the pure $\mathrm{CN}, \mathrm{SN}$, and CN/SN-2 mM electrodes. Furthermore, the photocurrent density of $\mathrm{CN} / \mathrm{SN}-4 \mathrm{mM}$ photoelectrode was around $2.1 \mathrm{~mA} \mathrm{~cm}^{-2}$ at $1 \mathrm{~V}$ vs. $\mathrm{Ag} / \mathrm{AgCl}$ in $0.2 \mathrm{M} \mathrm{Na}_{2} \mathrm{SO}_{4}$ under visible-light and it was around eight times higher than the pure $\mathrm{SN}$ electrode. The improved water splitting performance was owing to the enhanced surface area, light absorption ability, diminished reunion of charge carriers, and the synergistic effect in the heterostructured interface.

Kumar et al. successfully constructed heterostructured electrodes made of $\mathrm{NaNbO}_{3}$ nanofibers along with different concentrations $(2,4$, and $8 \mathrm{wt} . \%)$ of $\mathrm{g}-\mathrm{C}_{3} \mathrm{~N}_{4}$ nanosheets $(\mathrm{NNO} / \mathrm{CN})$ using facile hydrothermal followed by chemisorption techniques (Figure 6a) for better PEC water splitting performance [31]. The XRD results (Figure $6 b$ ) demonstrated that both the crystal phases of CN (interlayer stacking) and NNO (orthorhombic phase) were presented in the $\mathrm{NNO} / \mathrm{CN}$ heterostructured electrode. The surface morphology images (Figure 6c) confirmed the effective distribution of NNO nanofibers on the surface of CN nanosheets. The DRS analysis (Figure 6d) showed that the visible-light-harvesting ability was significantly enhanced in the $\mathrm{NNO} / \mathrm{CN}$ heterostructure electrode. The EIS results (Figure 6e) demonstrated that the $\mathrm{NNO} / \mathrm{CN}-4$ photoelectrode exhibited the lowest $\mathrm{R}_{\mathrm{ct}}$ value, and the $I-t$ results (Figure 6f) indicated that the $\mathrm{NNO} / \mathrm{CN}-4$ photoelectrode showed a sharp increase of photocurrent density with a quicker photoresponse than the other photoelectrodes. Moreover, the $\mathrm{NNO} / \mathrm{CN}-4$ photoelectrode showed a photocurrent density of $12.5 \mathrm{~mA} \mathrm{~cm}^{-2}$ at $1 \mathrm{~V}$ vs. $\mathrm{Ag} / \mathrm{AgCl}$ in $0.5 \mathrm{M} \mathrm{NaOH}$ electrolyte under visible-light, which was around three-times higher than the pristine NNO electrode $\left(4.3 \mathrm{~mA} \mathrm{~cm}{ }^{-2}\right)$. Thus, the formation of heterostructured electrode (Figure 6g) significantly enhanced the light-harvesting ability, separation of $\mathrm{e}^{-} / \mathrm{h}^{+}$pairs, and quicker interfacial charge transfer, which significantly improved the water-splitting ability.

A novel binary heterostructured electrode made of $\mathrm{Bi}_{2} \mathrm{WO}_{6}$ quantum dots (QDs) dispersed on the g- $\mathrm{C}_{3} \mathrm{~N}_{4}(\mathrm{CN} / \mathrm{BWQ})$ was prepared by a simplistic in-situ hydrothermal method [72]. The X-ray diffraction results confirmed the interlayer stacking of the $\mathrm{CN}$ units and the orthorhombic phase of BW, even after the formation of a heterostructured electrode. Furthermore, the morphological examination revealed that the BW QDs were uniformly distributed over the surface of $\mathrm{CN}$. When compared to the pristine samples, bandgap tuning was observed for the CN/BWQ heterostructured electrode, which significantly enhanced the visible-light-harvesting capability. Moreover, the CN/BWQ heterostructured electrode demonstrated the lowest $R_{\mathrm{ct}}$ value, the photocurrent density of CN/BWQ photoanode was observed around $0.39 \mu \mathrm{A} \mathrm{cm}{ }^{-2}$ at $1.23 \mathrm{~V}$ vs. RHE under visible-light illumination, and the current density value was about 2.4 and 1.8 times higher than the pristine $\mathrm{CN}$ and BWQ electrodes, respectively. Thus, forming a synergistic interfacial heterostructure and the Z-scheme mechanism could significantly enhance the water-splitting activity. The PEC performance of g- $\mathrm{C}_{3} \mathrm{~N}_{4}$-based various binary heterostructured electrodes is presented in Table 1. 

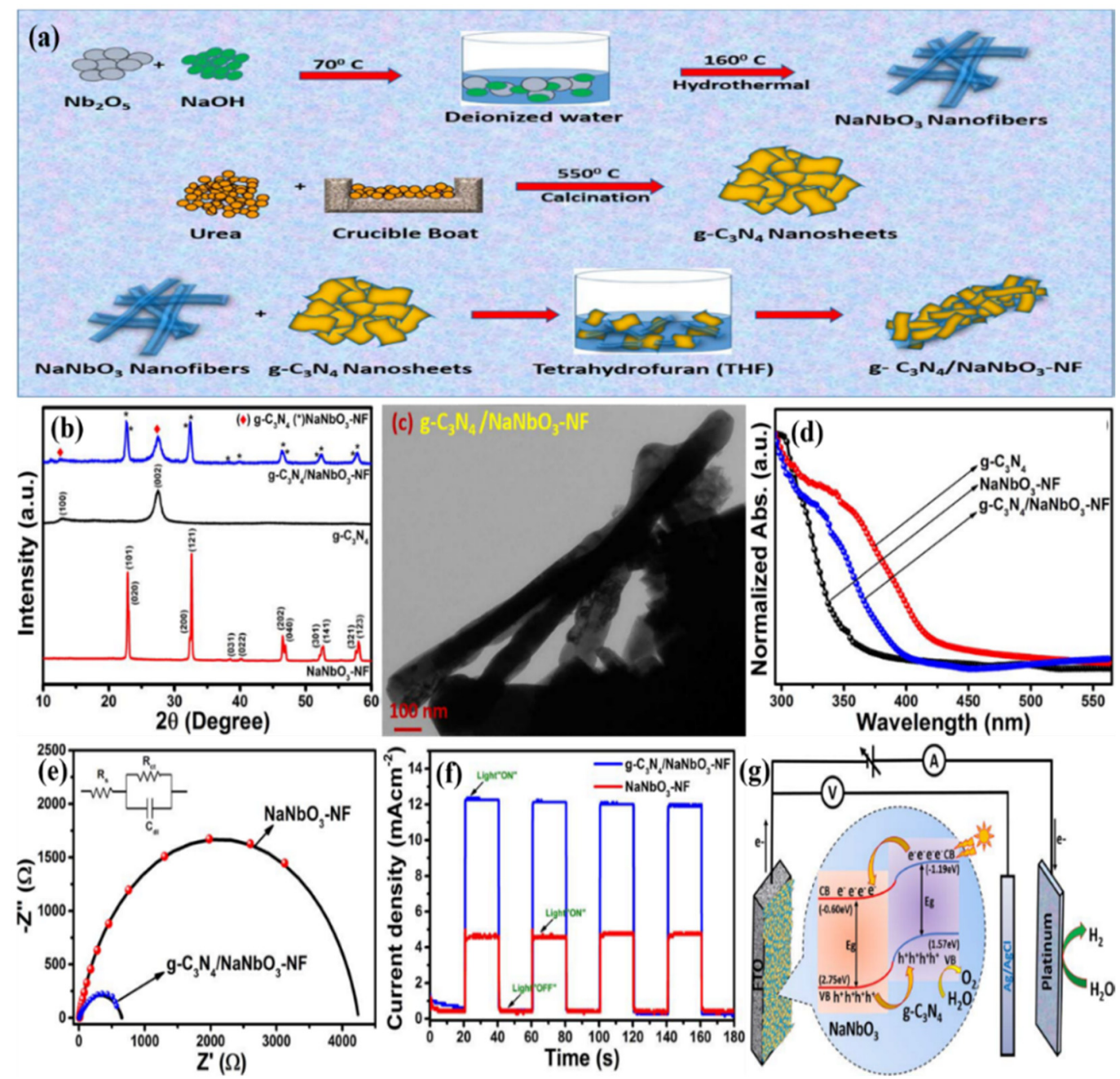

Figure 6. (a) Formation mechanism of NNO/CN heterostructured material, (b) XRD patterns, (c) TEM image of NNO/CN heterostructured material, (d) optical absorption spectra, (e) Nyquist plots, (f) $I-t$ curves, and (g) charge transfer mechanism of the NNO/CN heterostructured electrode. Reprinted with permission from reference [31], Copyright 2020, IOP.

Table 1. The PEC performance of $\mathrm{g}-\mathrm{C}_{3} \mathrm{~N}_{4}$-based binary heterostructured photoelectrodes.

\begin{tabular}{|c|c|c|c|c|c|c|}
\hline Photoelectrodes & $\begin{array}{l}\text { Synthesis } \\
\text { Methods }\end{array}$ & Potential (V) & Electrolytes & $\begin{array}{l}\text { Light } \\
\text { Sources }\end{array}$ & $\begin{array}{l}\text { Photocurrent } \\
\text { Density } \\
\left(\mathrm{mA} \mathrm{cm}^{-2}\right)\end{array}$ & Ref. \\
\hline $\mathrm{g}-\mathrm{C}_{3} \mathrm{~N}_{4} / \mathrm{ZnO}$ & Dip coating & 0.5994 vs. RHE & $0.5 \mathrm{M} \mathrm{Na}_{2} \mathrm{SO}_{4}$ & Visible & 0.952 & [73] \\
\hline $\mathrm{Pt} / \mathrm{g}-\mathrm{C}_{3} \mathrm{~N}_{4}$ & Dip coating & 0 vs. RHE & $0.1 \mathrm{M} \mathrm{Na}_{2} \mathrm{SO}_{4}$ & Solar & -2.5 & [74] \\
\hline $\mathrm{g}-\mathrm{C}_{3} \mathrm{~N}_{4} / \mathrm{CoP}$ & Impregnation & 0.4 vs. $\mathrm{Ag} / \mathrm{AgCl}$ & $0.05 \mathrm{M} \mathrm{Na}_{2} \mathrm{SO}_{4}$ & Solar & 0.15 & [75] \\
\hline $\mathrm{g}-\mathrm{C}_{3} \mathrm{~N}_{4} / \mathrm{BiVO}_{4}$ & Hydrothermal & 1.23 vs. RHE & $1 \mathrm{M} \mathrm{KOH}$ & visible & 0.021 & [76] \\
\hline $\mathrm{g}-\mathrm{C}_{3} \mathrm{~N}_{4} / \mathrm{CdS}$ & $\begin{array}{l}\text { Electrophoretic } \\
\text { and chemical } \\
\text { bath deposition }\end{array}$ & 0 vs. $\mathrm{Ag} / \mathrm{AgCl}$ & $0.5 \mathrm{M} \mathrm{Na}_{2} \mathrm{SO}_{3}$ & Visible & 5.4 & [77] \\
\hline $\mathrm{g}-\mathrm{C}_{3} \mathrm{~N}_{4} / \mathrm{CNTs}$ & $\begin{array}{l}\text { Liquid } \\
\text { exfoliation }\end{array}$ & 0 vs. SCE & $0.5 \mathrm{M} \mathrm{Na}_{2} \mathrm{SO}_{4}$ & Visible & 0.0018 & [78] \\
\hline $\mathrm{g}-\mathrm{C}_{3} \mathrm{~N}_{4} / \mathrm{SnO}{ }_{2}$ & $\begin{array}{c}\text { Pulsing } \\
\text { electrophoresis }\end{array}$ & 0.2 vs. $\mathrm{Ag} / \mathrm{AgCl}$ & $0.1 \mathrm{M} \mathrm{NaOH}$ & Solar & 1.8 & [79] \\
\hline $\mathrm{g}-\mathrm{C}_{3} \mathrm{~N}_{4} / \mathrm{BiVO}_{4}$ & Sol-gel & -- vs. $\mathrm{Ag} / \mathrm{AgCl}$ & $0.1 \mathrm{M} \mathrm{Na}_{2} \mathrm{SO}_{4}$ & Solar & 0.00046 & [80] \\
\hline $\mathrm{g}-\mathrm{C}_{3} \mathrm{~N}_{4} / \mathrm{InVO}_{4}$ & $\begin{array}{l}\text { Mixing } \\
\text { calcination }\end{array}$ & 0.9 vs. $\mathrm{Ag} / \mathrm{AgCl}$ & $0.1 \mathrm{M} \mathrm{Na}_{2} \mathrm{SO}_{4}$ & Solar & 0.013 & [81] \\
\hline $\mathrm{g}-\mathrm{C}_{3} \mathrm{~N}_{4} / \mathrm{In}_{2} \mathrm{~S}_{3}$ & Wet chemical & 1.5 vs. $\mathrm{Ag} / \mathrm{AgCl}$ & $0.1 \mathrm{M} \mathrm{Na}_{2} \mathrm{SO}_{3}$ & Visible & 0.005 & [82] \\
\hline $\mathrm{g}-\mathrm{C}_{3} \mathrm{~N}_{4} / \mathrm{Cu}_{2} \mathrm{O}$ & $\begin{array}{l}\text { Electrophoretic } \\
\text { deposition }\end{array}$ & -0.4 vs. $\mathrm{Ag} / \mathrm{AgCl}$ & $0.1 \mathrm{M} \mathrm{NaNO}_{3}$ & Visible & -1.38 & [83] \\
\hline
\end{tabular}


Table 1. Cont.

\begin{tabular}{|c|c|c|c|c|c|c|}
\hline Photoelectrodes & $\begin{array}{l}\text { Synthesis } \\
\text { Methods }\end{array}$ & Potential (V) & Electrolytes & $\begin{array}{l}\text { Light } \\
\text { Sources }\end{array}$ & $\begin{array}{l}\text { Photocurrent } \\
\text { Density } \\
\left(\mathrm{mA} \mathrm{cm}^{-2}\right)\end{array}$ & Ref. \\
\hline $\begin{array}{c}\text { Phosphorus } \\
\text { doped g- } \mathrm{C}_{3} \mathrm{~N}_{4}\end{array}$ & Sintering & 1.2 vs. $\mathrm{Ag} / \mathrm{AgCl}$ & $0.5 \mathrm{M} \mathrm{Na}_{2} \mathrm{SO}_{4}$ & $\begin{array}{l}\text { Near- } \\
\text { infrared }\end{array}$ & 0.0014 & {$[84]$} \\
\hline $\mathrm{g}-\mathrm{C}_{3} \mathrm{~N}_{4} / \mathrm{BiVO}_{4}$ & Electrodeposition & 1.23 vs. RHE & $0.5 \mathrm{M} \mathrm{Na}_{2} \mathrm{SO}_{4}$ & Solar & 0.42 & [85] \\
\hline $\mathrm{g}-\mathrm{C}_{3} \mathrm{~N}_{4} / \mathrm{CuO}$ & Co-precipitation & 1.2 vs. $\mathrm{Ag} / \mathrm{AgCl}$ & - & Visible & 0.68 & [86] \\
\hline $\mathrm{g}-\mathrm{C}_{3} \mathrm{~N}_{4} / \mathrm{MoS}_{2}$ & Solvothermal & -0.4 vs. $\mathrm{Ag} / \mathrm{AgCl}$ & $0.1 \mathrm{M}$ PBS & Solar & 0.037 & [87] \\
\hline $\mathrm{g}-\mathrm{C}_{3} \mathrm{~N}_{4} @ \mathrm{CuTi}$ & Hydrothermal & 0.65 vs. $\mathrm{Ag} / \mathrm{AgCl}$ & $1 \mathrm{M} \mathrm{KOH}$ & Visible & 0.014 & [88] \\
\hline $\mathrm{C}_{3} \mathrm{~N}_{4} / \stackrel{\mathrm{g}-}{\mathrm{LaFeO}_{3}}$ & $\begin{array}{l}\text { Magnetron } \\
\text { sputtering }\end{array}$ & -0.3 vs. $\mathrm{Ag} / \mathrm{AgCl}$ & $0.1 \mathrm{M} \mathrm{Na}_{2} \mathrm{SO}_{4}$ & Solar & 0.004 & [89] \\
\hline $\begin{array}{c}\mathrm{g}-\mathrm{C}_{3} \mathrm{~N}_{4} @ \mathrm{Si} \\
\mathrm{NWs}\end{array}$ & $\begin{array}{l}\text { Metal-assisted } \\
\text { etching, and } \\
\text { liquid atomic } \\
\text { layer deposition }\end{array}$ & 1 vs. Pt & $0.5 \mathrm{M} \mathrm{Na}_{2} \mathrm{SO}_{4}$ & Visible & 0.316 & {$[90]$} \\
\hline $\begin{array}{l}\text { Cobalt doped } \\
\text { g- } \mathrm{C}_{3} \mathrm{~N}_{4}\end{array}$ & Calcination & $\mathrm{Ag} / \mathrm{AgCl}$ & $0.1 \mathrm{M} \mathrm{Na}_{2} \mathrm{SO}_{4}$ & Solar & 0.058 & [91] \\
\hline $\mathrm{g}-\mathrm{C}_{3} \mathrm{~N}_{4} @ \mathrm{CoFe}$ & Solvothermal & 0.2 vs. $\mathrm{Ag} / \mathrm{AgCl}$ & $1 \mathrm{M} \mathrm{KOH}$ & Visible & 0.196 & [92] \\
\hline
\end{tabular}

\section{4. g- $\mathrm{C}_{3} \mathrm{~N}_{4}$-Based Ternary Heterostructured Photoelectrodes for PEC Water Splitting}

Numerous efforts have been executed to fabricate g- $\mathrm{C}_{3} \mathrm{~N}_{4}$-based binary heterostructured electrodes to overcome the constraints and improve the PEC water splitting ability. However, the PEC performance is still limited and not up to the target of practical applications. To overcome these issues, $\mathrm{g}-\mathrm{C}_{3} \mathrm{~N}_{4}$-based complex compounds containing three components have been introduced, and some of the results are discussed here. A novel hybrid ternary anatase $\mathrm{TiO}_{2} /$ rutile $\mathrm{TiO}_{2} / \mathrm{g}-\mathrm{C}_{3} \mathrm{~N}_{4}(\mathrm{~A} / \mathrm{R} / \mathrm{CN}$ ) heterostructured electrode was prepared with different mass ratios of $\mathrm{CN}(20,30,40,50$, and $60 \mathrm{mg})$ using a facile thermoset hybrid technique for the enhancement of water splitting performance [93]. The XRD result confirmed the anatase and rutile phases of $\mathrm{TiO}_{2}$ and the interlayer stacking of the $\mathrm{CN}$ units. The electron microscopy results validated that the $\mathrm{TiO}_{2} \mathrm{NPs}_{\text {sere distributed }}$ over the surface of $\mathrm{CN}$, which signifies the formation of a heterostructured electrode. The light-harvesting capacity systematically improved towards the visible region in the case of the ternary heterostructured electrode. From the EIS results, the A/R/CN40 heterostructured electrode showed the lowest charge transfer resistance value than the pure P25, CN, and $\mathrm{A} / \mathrm{R} / \mathrm{CN} 20, \mathrm{~A} / \mathrm{R} / \mathrm{CN} 30, \mathrm{~A} / \mathrm{R} / \mathrm{CN} 50$, and $\mathrm{A} / \mathrm{R} / \mathrm{CN} 60$ heterostructured electrodes. Further, the photocurrent density of the A/R/CN40 photoanode was superior to the other electrodes under solar light illumination. Thus, the formation of interfacial interactions among the three components could improve the migration of charge carriers with more separation, which further enhanced the PEC water splitting capability.

Reddy and co-workers have developed a novel ternary electrode made of CdS NPs and $\mathrm{Fe}_{3} \mathrm{O}_{4}$ nanocubes dispersed over the g- $\mathrm{C}_{3} \mathrm{~N}_{4}$ nanosheets (CS/FO/CN) using two-step solvothermal techniques for the enhanced PEC water splitting performance [37]. The morphology results demonstrated that the CdS NPs entered into the $\mathrm{Fe}_{3} \mathrm{O}_{4}$ lattices and were distributed on the surface of $\mathrm{CN}$ nanosheets. The $\mathrm{XRD}$ results confirmed the presence of the hexagonal phase of $\mathrm{CdS}$, the magnetite phase of $\mathrm{Fe}_{3} \mathrm{O}_{4}$, the interlayer stacking of $\mathrm{CN}$ in $\mathrm{CS} / \mathrm{FO} / \mathrm{CN}$ heterostructured electrode, and the heterostructure formation did not affect the individual phases. The $\mathrm{CS} / \mathrm{FO} / \mathrm{CN}$ electrode showed a superior specific surface area of $40.022 \mathrm{~m}^{2} \mathrm{~g}^{-1}$. Further, the $\mathrm{CS} / \mathrm{FO} / \mathrm{CN}$ ternary heterostructured electrode showed enlarged light-harvesting performance. The charge transfer resistance of CS/FO/CN ternary heterostructured electrode was significantly reduced when compared to $\mathrm{CdS}$, CN@CS, and CS@FO electrodes upon visible-light irradiation. The photocurrent density of the CS/FO/CN ternary heterostructured electrode showed around $0.0238 \mathrm{~mA} \mathrm{~cm}^{-2}$ at $0.2 \mathrm{~V}$ vs. $\mathrm{Ag} / \mathrm{AgCl}$ under visible-light irradiation, and it was around 5.95, 4.76, and 7.93 times higher than CdS, CN@CS, and CS@FO electrodes, respectively. This improvement in the PEC performance was ascribed to the ternary interfacial charge transport, separation efficiency of $\mathrm{e}^{-} / \mathrm{h}^{+}$pairs, and the facile transportation of charge carriers. 
Bhandary and colleagues fabricated a bimetallic AgNi alloy surrounded by g- $\mathrm{C}_{3} \mathrm{~N}_{4}$ nanosheets $(\mathrm{CN} / \mathrm{AgNi})$ electrodes using a facile one-pot solid-state heat treatment method to improve the PEC water splitting capability [94]. The structural and morphological studies confirmed the heterostructure formation with a successful decoration of bimetallic $\mathrm{AgNi}$ alloy over the surface of $\mathrm{g}-\mathrm{C}_{3} \mathrm{~N}_{4}$ nanosheets. After the formation of the heterostructure, the light absorption capability remarkably improved. Further, the EIS results confirmed that the constructed $\mathrm{CN} / \mathrm{AgNi}$ heterostructured electrode showed the lowest $\mathrm{R}_{\mathrm{ct}}$ value among the pure samples. Furthermore, the $\mathrm{CN} / \mathrm{AgNi}$ photoelectrode showed the highest photocurrent density of $1.29 \mathrm{~mA} \mathrm{~cm}^{-2}$ at $1.0 \mathrm{~V}$ vs. $\mathrm{Ag} / \mathrm{AgCl}$ in $1.0 \mathrm{M} \mathrm{NaOH}$ electrolyte under visible light, and the value was more significant than the $\mathrm{CN}, \mathrm{CN} / \mathrm{Ag}$, and $\mathrm{CN} / \mathrm{Ni}$ electrodes. Nevertheless, the $\mathrm{CN} / \mathrm{AgNi}$ heterostructured electrode exhibited excellent stability, and thus the formation of a heterostructure could effectively improve the migration of charge carriers with lower charge transfer resistance and suppress the reunion of $\mathrm{e}^{-} / \mathrm{h}^{+}$ pairs.

The novel ternary heterostructured electrodes of $\mathrm{Ag}_{3} \mathrm{PO}_{4} / \mathrm{Ag}_{2} \mathrm{MoO}_{4}$ materials combined with various concentrations $(0.4,0.8$, and $1.2 \mathrm{wt} . \%)$ of multilayered $\mathrm{g}-\mathrm{C}_{3} \mathrm{~N}_{4}$ nanosheets $(\mathrm{AP} / \mathrm{AM} / \mathrm{CN})$ were systematically fabricated using the in-situ co-precipitation technique by Liu and colleagues [95]. The XRD results showed the formation of the cubic phase of $\mathrm{Ag}_{3} \mathrm{PO}_{4}$ and $\mathrm{Ag}_{2} \mathrm{MoO}_{4}$, the interlayer stacking of $\mathrm{CN}$, and the ternary AP/AM/CN heterostructured electrode contained all three phases. The morphology results demonstrated that both the AP and AM NPs were distributed over the surface of $\mathrm{CN}$ nanosheets, which confirmed the establishment of the ternary heterostructured electrode. Further, the FTIR and Raman spectra results evidently showed synergistic interactions among AP/AM and $\mathrm{CN}$ interfaces. The visible-light-harvesting ability was considerably enhanced through the formation of ternary $\mathrm{AP} / \mathrm{AM} / \mathrm{CN}$ heterostructured electrodes when compared to the $\mathrm{CN}$, $\mathrm{AP}, \mathrm{AM}$, and AP/AM electrodes. From the EIS results, the ternary AP/AM/CN photoanode showed the lowest charge transfer resistance value when compared to the $\mathrm{CN}, \mathrm{AP}, \mathrm{AM}$, and AP/AM electrodes. Moreover, the photocurrent density of the ternary AP/AM/CN photoelectrode was superior to the other samples under solar light illumination. Thus, the enlarged solar light absorption ability could effectively diminish the reunion of charge carriers and the dual Z-scheme charge carrier pathway that eventually enhanced the PEC water splitting ability.

A novel hybrid ternary g- $\mathrm{C}_{3} \mathrm{~N}_{4} / \mathrm{Au}-\mathrm{SnO}_{2}$ QDs (CN/Au/SQD) heterostructured electrode was prepared with different mass ratios of Au-SQD (10, 20, and $30 \mathrm{mg}$ ), using calcination and sonication methods (Figure 7a) for the enhancement of PEC water splitting performance [96]. The XRD results revealed the presence of the tetragonal phase of $\mathrm{SnO}_{2}$, interlayer stacking of the $\mathrm{CN}$ units, and the metallic phase of $\mathrm{Au}$. The electron microscopy results (Figure $7 \mathrm{~b}$ ) confirmed that the Au-SQDs were distributed over the surface of $\mathrm{CN}$, which signifies the heterostructure formation. The light-harvesting efficiency (Figure 7c) was systematically improved towards the visible region through the heterostructure formation. The PL spectra (Figure $7 \mathrm{~d}$ ) of $\mathrm{CN} / \mathrm{Au} / \mathrm{SQD}$ heterostructured electrode showed a very weak intensity compared to the SQD, CN, and Au-SQD samples. From the EIS results, the CN/Au/SQD ternary electrode showed the lowest $\mathrm{R}_{\mathrm{ct}}$ value than the SQD, CN, and $\mathrm{Au}-\mathrm{SQD}$ electrodes. Furthermore, the $\mathrm{CN} / \mathrm{Au} / \mathrm{SQD}$ photoelectrode displayed the superior photocurrent density (Figure $7 \mathrm{e}$ ) of $0.0402 \mathrm{~mA} \mathrm{~cm}^{-2}$ at $1.0 \mathrm{~V}$ vs. $\mathrm{Ag} / \mathrm{AgCl}$ in $0.1 \mathrm{M} \mathrm{Na}_{2} \mathrm{SO}_{3}$ electrolyte under visible-light irradiation, and the value was significantly greater than the SQD, CN, and Au-SQD electrodes. Thus, the fabrication of metal-semiconductor combined with $\mathrm{CN}$ ternary heterostructured electrodes (Figure $7 \mathrm{f}$ ) could improve the migration of charge carriers with more separation efficiency, which further enhanced the PEC water splitting performance. 


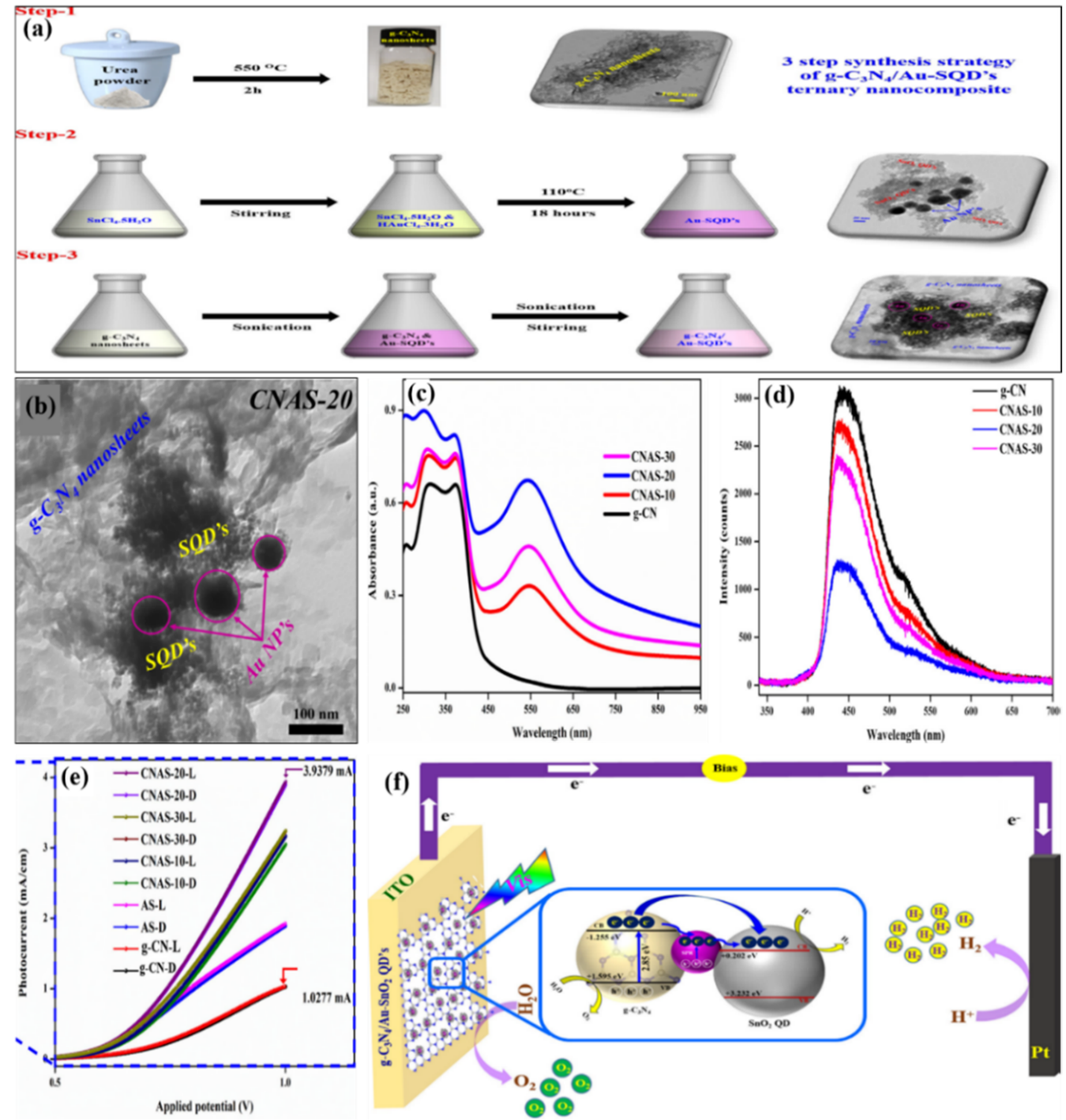

Figure 7. (a) Formation mechanism of CN/Au-SQD ternary heterostructured material, (b) TEM image of CN/Au-SQD heterostructured material, (c) optical absorption spectra, (d) PL spectra, (e) LSV curves, and (f) charge transfer mechanism of the CN/Au-SQD ternary heterostructured electrodes. Reprinted with permission from reference [96], Copyright 2020, Elsevier.

$\mathrm{Li}$ and co-workers systematically fabricated $0 \mathrm{D} \mathrm{Bi}_{2} \mathrm{O}_{3} \mathrm{NPs}$ encapsulated with $\mathrm{BiPO}_{4}$ nanorods that were distributed over the surface of $\mathrm{g}-\mathrm{C}_{3} \mathrm{~N}_{4}$, which formed the $\mathrm{CN} / \mathrm{BO} / \mathrm{BP}$ ternary heterostructured electrode using the facile hydrothermal method followed by calcination process [97]. The XRD results demonstrated that the ternary $\mathrm{CN} / \mathrm{BO} / \mathrm{BP}$ heterostructured electrode exhibited g- $\mathrm{C}_{3} \mathrm{~N}_{4}, \mathrm{Bi}_{2} \mathrm{O}_{3}$, and $\mathrm{BiPO}_{4}$ phases, confirming the presence of individual components. The morphology results showed that the $\mathrm{Bi}_{2} \mathrm{O}_{3} \mathrm{NPs}$ were anchored over $\mathrm{BiPO}_{4}$ nanorods, and the binary $\mathrm{BO} / \mathrm{BP}$ heterostructured material was distributed over the surface of the $\mathrm{g}-\mathrm{C}_{3} \mathrm{~N}_{4}$ nanosheets. When compared to pure samples, the light absorption efficiency of the $\mathrm{CN} / \mathrm{BO} / \mathrm{BP}$ heterostructured electrode enhanced towards the visible region. From the EIS analysis, the ternary $\mathrm{CN} / \mathrm{BO} / \mathrm{BP}$ photoanode exhibited the lowest $\mathrm{R}_{\mathrm{ct}}$ value compared to the pure $\mathrm{CN}, \mathrm{BO}, \mathrm{BP}, \mathrm{CN} / \mathrm{BP}, \mathrm{BO} / \mathrm{BP}$ electrodes. From the LSV results, the CN/BO/BP photoanode showed a photocurrent density of 0.095 $\mathrm{mA} \mathrm{cm}{ }^{-2}$ at $1.25 \mathrm{~V}$ vs. $\mathrm{Ag} / \mathrm{AgCl}$ in $0.1 \mathrm{M} \mathrm{Na}_{2} \mathrm{SO}_{4}$ electrolyte under solar light irradiation, and the value was 2.4 and 1.3 times superior to the $\mathrm{BP}$ and $\mathrm{BO} / \mathrm{BP}$ electrodes, respectively. This enhanced PEC performance could be ascribed to the formation of the interfacial heterostructure with the Z-scheme process, which hinders the recombination of charge carriers and higher solar-light absorption ability. 
Chaudhary et al. have developed a novel ternary heterostructured electrode consisting of the $\mathrm{TiO}_{2} \mathrm{NPs}$ with carbon nanotubes that dispersed over the $\mathrm{g}-\mathrm{C}_{3} \mathrm{~N}_{4}$ nanosheets (TO/CN/CNT) using a facile hydrothermal method [98]. The XRD results (Figure 8a) confirmed the anatase phase of $\mathrm{TiO}_{2}$, the graphitic nature of CNT, and the interlayer stacking of $\mathrm{CN}$. The morphology results (Figure $8 \mathrm{~b}$ ) displayed that the $\mathrm{TiO}_{2} \mathrm{NPs}$ and CNTs were decorated on the surface of $\mathrm{CN}$ nanosheets. Further, the TO/CN/CNT ternary heterostructured electrode showed an enlarged light-harvesting performance. The $R_{c t}$ value (Figure 8c) of the $\mathrm{TO} / \mathrm{CN} / \mathrm{CNT}$ ternary heterostructured electrode was significantly reduced compared to the $\mathrm{TO}, \mathrm{CN}$, and TO/CN electrodes under visible-light illumination. The photocurrent density (Figure $8 \mathrm{~d}$ ) of the TO/CN/CNT ternary electrode showed $2.43 \mathrm{~mA} \mathrm{~cm}^{-2}$ at $0.6 \mathrm{~V}$ vs. $\mathrm{Ag} / \mathrm{AgCl}$ in $0.5 \mathrm{M} \mathrm{Na}_{2} \mathrm{SO}_{4}$ electrolyte under visible-light, and the current density value was around 6.4, and 3.2 times higher than the $\mathrm{CN}, \mathrm{TO} / \mathrm{CN}$ photoelectrodes, respectively. Thus, the formation of interfacial interactions among the three components (Figure 8e) could effectively improve the migration of charge carriers with more separation, which in turn enhanced the PEC water splitting efficiency.

$\mathrm{Si}$ and co-workers systematically fabricated graphdiyne (GDY)-anchored $\mathrm{g}-\mathrm{C}_{3} \mathrm{~N}_{4} / \mathrm{NiFe}-$ layered double hydroxide (CN/GDY/NF) electrode via the facile hydrothermal method [99]. The XRD results revealed that CN, GDY, and NF crystal phases were presented in the CN/GDY/NF heterostructured electrode without any impurity phases. Further, the FTIR and XPS results confirmed that the heterostructured material consisted of individual compounds. The CN/GDY/NF heterostructured material presented a higher specific surface area of $208.75 \mathrm{~m}^{2} \mathrm{~g}^{-1}$ than the pure CN $\left(126.32 \mathrm{~m}^{2} \mathrm{~g}^{-1}\right)$, GDY $\left(95.03 \mathrm{~m}^{2} \mathrm{~g}^{-1}\right)$, and NF $\left(42.63 \mathrm{~m}^{2} \mathrm{~g}^{-1}\right)$ materials. The visible-light-harvesting ability was significantly enhanced after forming the CN/GDY/NF heterostructured electrode, and the PL intensity was diminished compared to the pristine CN, GDY, and NF samples. From the EIS results, the $\mathrm{CN} / \mathrm{GDY} / \mathrm{NF}$ photoelectrode showed the lowest $R_{\mathrm{ct}}$ value than the pure CN, GDY, and NF electrodes. Furthermore, the photocurrent density of ternary CN/GDY/NF photoelectrode was observed around $0.178 \mathrm{~mA} \mathrm{~cm}^{-2}$ at $1.4 \mathrm{~V}$ vs. RHE under visible light, and the photocurrent density value was around 45 times higher than the pristine $\mathrm{CN}$ electrode. The enhanced water splitting activity was ascribed to the formation of synergistic interactions among the ternary components, which emphasized the visible-light absorption ability and quick transfer of charge carriers with lower charge-transfer resistance.

Gopalakrishnan et al. adopted the spin-coating technique and successfully fabricated the heterostructured electrode in which $\mathrm{SrTiO}_{3} \mathrm{NPs}$ covered on the surface of $g-\mathrm{C}_{3} \mathrm{~N}_{4}$ nanosheets and coupled with silicon nanowires (ST/CN/Si) [100]. The crystallographic analysis confirmed the formation of ST, CN, and Si phases in the ST/CN/Si heterostructured electrode without any impurity phases. The morphology results demonstrated the uniform distribution of ST nanoparticles and Si nanowires on the surface of $\mathrm{g}-\mathrm{C}_{3} \mathrm{~N}_{4}$, which confirmed the formation of a synergistic interfacial heterostructure. Further, the light-harvesting ability was significantly enhanced towards the visible region through the formation of a ternary ST/CN/Si heterostructured electrode. From the EIS analysis, the $\mathrm{ST} / \mathrm{CN} / \mathrm{Si}$ photocathode exhibited the lowest charge transfer resistance than the pure $\mathrm{CN}$, ST, Si, and CN@Si electrodes. The photocurrent density of the ST/CN/Si heterostructured electrode showed around $28 \mathrm{~mA} \mathrm{~cm}^{-2}$ at $0.8 \mathrm{~V}$ vs. RHE in $0.5 \mathrm{M} \mathrm{Na}_{2} \mathrm{SO}_{4}$ electrolyte under visible light, and this current density value was superior to the other electrodes. Therefore, the introduction of Si nanowires and ST nanoparticles on the surface of CN considerably enriched the light-harvesting ability, separation of $\mathrm{e}^{-} / \mathrm{h}^{+}$pairs, and quicker interfacial charge transfer, which significantly progressed the water-splitting ability. 

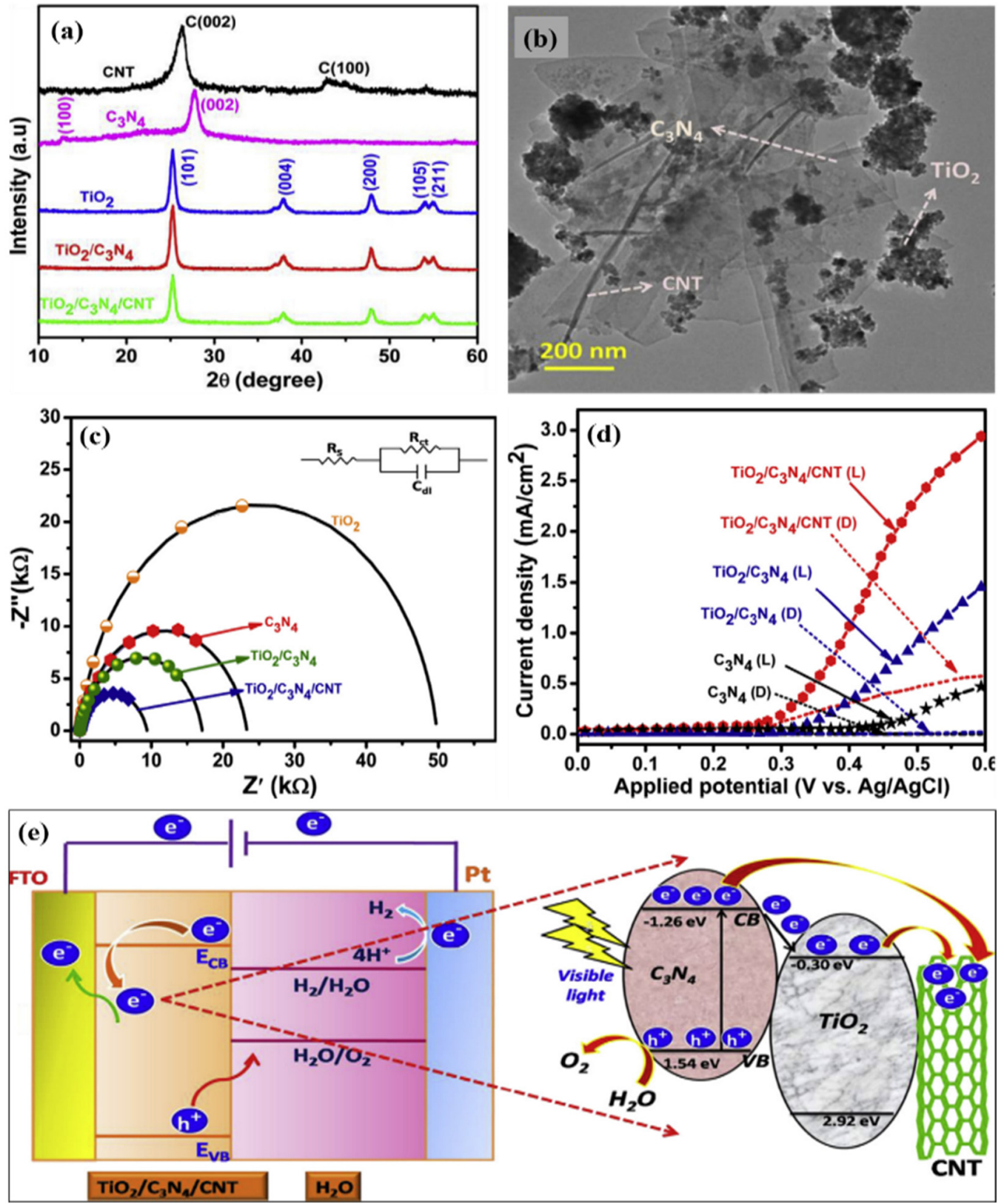

Figure 8. (a) XRD patterns, (b) TEM image of TO/CN/CNT heterostructured material, (c) Nyquist plots, (d) LSV curves, and (e) charge transfer mechanism of the TO/CN/CNT ternary heterostructured electrode. Reprinted with permission from reference [98], Copyright 2020, Elsevier.

To enhance the utility of visible-light and diminish the reunion of charge carriers, a novel fluorine-doped, chlorine-intercalated g- $\mathrm{C}_{3} \mathrm{~N}_{4}$ combined with various concentrations of $\mathrm{BiOI}(10,25,57$, and $75 \%$ )-based $\mathrm{CNF}-\mathrm{Cl} / \mathrm{BI}$ heterostructured electrodes was prepared using a facile in-situ hydrothermal technique by Alam and co-workers [101]. The XRD results confirmed the interlayer stacking of the $\mathrm{CN}$ units and the tetragonal phase of $\mathrm{BI}$ even after the formation of a CNF-Cl/BI heterostructure. The morphology results demonstrated that the BI nanoplates were uniformly covered on the surface of the CNF-Cl electrode. The bandgap tuning was observed for the $\mathrm{CNF}-\mathrm{Cl} / \mathrm{BI}$ heterostructured electrode when compared to pure samples, which significantly enhanced the visible-light absorption ability. From the EIS results, the $\mathrm{CNF}-\mathrm{Cl} / \mathrm{BI} 50 \%$ heterostructured electrode exhibited the lowest $\mathrm{R}_{\mathrm{ct}}$ value than the remaining samples. Moreover, the photocurrent density of $\mathrm{CNF}-\mathrm{Cl} / \mathrm{BI} 50 \%$ photoanode was observed around $1.28 \mathrm{~mA} \mathrm{~cm}^{-2}$ at $1.23 \mathrm{~V}$ vs. RHE under visible-light illumination, and the value was around 4.6 and 3.2 times higher than the $\mathrm{CNF}-\mathrm{Cl}$ and $\mathrm{BI}$ 
electrodes, respectively. Thus, the formation of synergistic interfaces, improved charge separation, and the enlarged light-harvesting ability significantly enhanced the PEC watersplitting performance.

Wu et al. systematically fabricated a novel $\mathrm{Bi}_{2} \mathrm{MoO}_{6}-\mathrm{Ru}$ binary heterostructured material anchored on the surface of $\mathrm{g}-\mathrm{C}_{3} \mathrm{~N}_{4}(\mathrm{BMO} / \mathrm{Ru} / \mathrm{CN})$ using a facile hydrothermal method (Figure 9a) [102]. The XRD results (Figure 9b) demonstrated that all the crystal phases of $\mathrm{BMO}, \mathrm{Ru}$, and $\mathrm{CN}$ were presented in the $\mathrm{BMO} / \mathrm{Ru} / \mathrm{CN}$ heterostructured electrode without any impurity phases. Further, the peak shift of XPS confirmed the formation of ternary $\mathrm{BMO} / \mathrm{Ru} / \mathrm{CN}$ heterostructured material. The visible-light-harvesting ability (Figure 9c) was significantly enhanced after the $\mathrm{BMO} / \mathrm{Ru} / \mathrm{CN}$ heterostructure formation, and the PL intensity was diminished compared to the $\mathrm{BMO}, \mathrm{CN}, \mathrm{BMO} / \mathrm{Ru}, \mathrm{Ru} / \mathrm{CN}$, and $\mathrm{BMO} / \mathrm{CN}$ samples. The morphology results (Figure $9 \mathrm{~d}$ and e) revealed the uniform distribution of BMO microspheres and Ru NPs on the surface of CN. From the EIS results (Figure 9f), the $\mathrm{BMO} / \mathrm{Ru} / \mathrm{CN}$ heterostructured electrode showed the lowest $\mathrm{R}_{\mathrm{ct}}$ value than the BMO, $\mathrm{CN}, \mathrm{BMO} / \mathrm{Ru}, \mathrm{Ru} / \mathrm{CN}$, and $\mathrm{BMO} / \mathrm{CN}$ electrodes. Furthermore, the photocurrent density of ternary $\mathrm{BMO} / \mathrm{Ru} / \mathrm{CN}$ photoelectrode was around $1.0 \mathrm{~mA} \mathrm{~cm}^{-2}$ at $1.4 \mathrm{~V} \mathrm{vs.} \mathrm{Ag} / \mathrm{AgCl}$ under visible light, and the obtained photocurrent density was approximately 25 times higher than the $\mathrm{BMO} / \mathrm{CN}$ electrode. The enhanced water splitting performance (Figure $9 \mathrm{~g}$ ) was ascribed to the formation of synergistic coupling among the ternary components, which emphasized the visible-light absorption ability and facile transportation of charge carriers with a lower $\mathrm{R}_{\mathrm{ct}}$ value.

Patnaik and colleagues successfully synthesized the various concentrations $(2,4$, 6, and $8 \mathrm{wt} . \%)$ of $\mathrm{Cu}$-promoted $\mathrm{MoO}_{3} / \mathrm{g}-\mathrm{C}_{3} \mathrm{~N}_{4}(\mathrm{Cu} / \mathrm{MO} / \mathrm{CN})$ hybrid heterostructured electrode using the in-situ pyrolysis followed by the impregnation techniques [103]. The $\mathrm{XRD}$ results confirmed that the interlayer stacking of the $\mathrm{CN}$ units, the orthorhombic phase of $\mathrm{MoO}_{3}$, and the heterostructure formation did not influence the individual phase. The morphological investigation inferred that the irregular-shaped $\mathrm{MoO}_{3}$ nanocrystals and $\mathrm{Cu}$ nanoparticles dispersed on the $\mathrm{g}-\mathrm{C}_{3} \mathrm{~N}_{4}$ surface. Further, the visible-light absorption ability was improved by forming the heterostructure, and the distribution of $\mathrm{Cu}$ NPs was confirmed by the occurrence of a surface plasmon resonance band. From the EIS results, the $2 \% \mathrm{Cu} / \mathrm{MO} / \mathrm{CN}$ heterostructured electrode exhibited the lowest charge-transfer resistance value among other samples. Further, the $2 \% \mathrm{Cu} / \mathrm{MO} / \mathrm{CN}$ heterostructured electrode showed a photocurrent density of around $5.1 \mathrm{~mA} \mathrm{~cm}{ }^{-2}$ using $0.5 \mathrm{M} \mathrm{Na}_{2} \mathrm{SO}_{4}$ electrolyte under visible-light illumination, which was higher than the other electrodes. Thus, the synergistic interactions having rich-oxygen vacancies could effectively improve the mobility of charge carriers and diminish the reunion of electron/hole pairs, which enhanced the PEC performance. The PEC performance of $\mathrm{g}-\mathrm{C}_{3} \mathrm{~N}_{4}$-based various ternary heterostructured electrodes is presented in Table 2. 

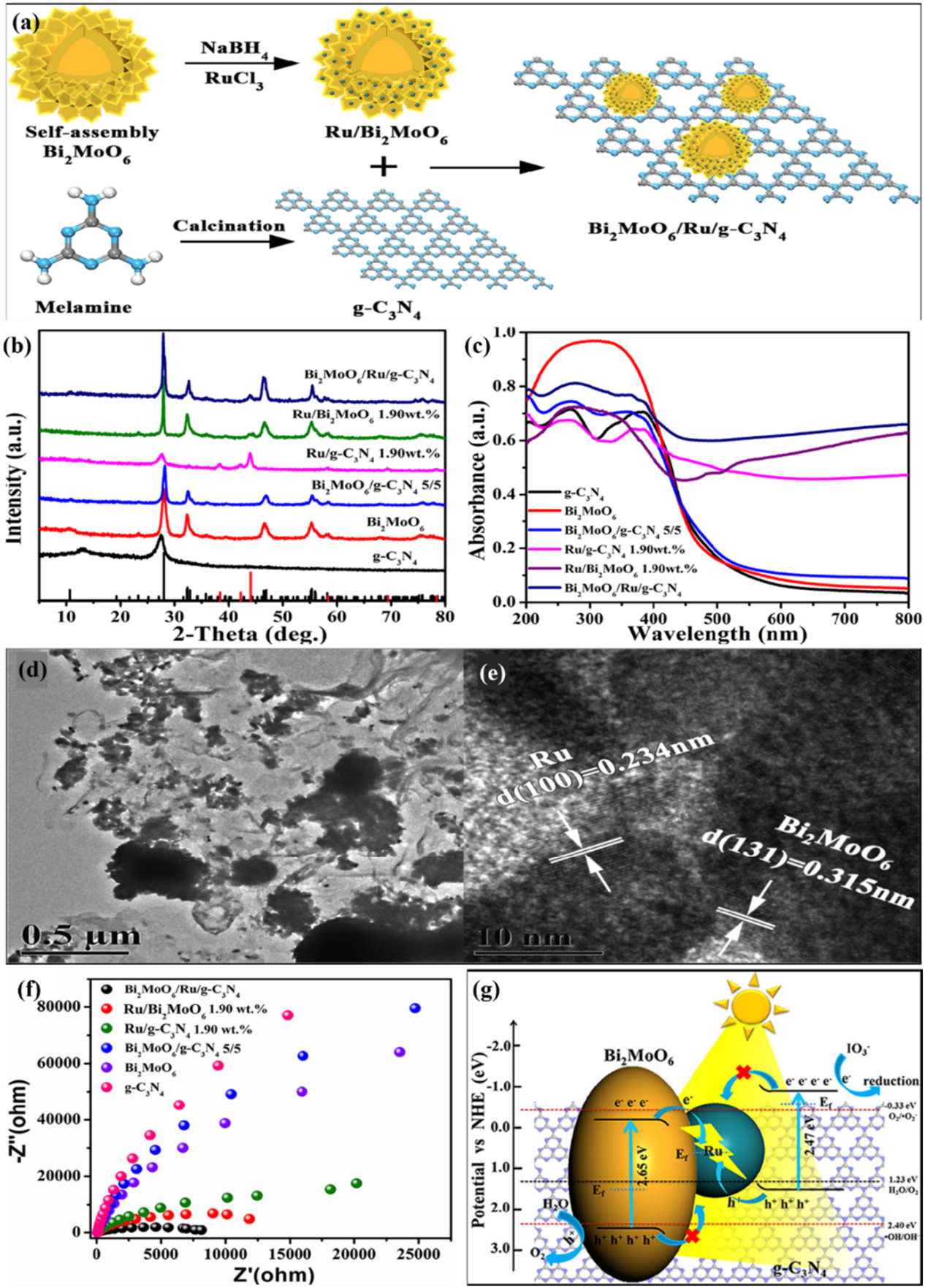

Figure 9. (a) Formation mechanism of the $\mathrm{BO} / \mathrm{Ru} / \mathrm{CN}$ ternary heterostructured material, (b) XRD patterns, (c) optical absorption spectra, (d) TEM image, (e) HRTEM image of BO/Ru/CN heterostructured material, (f) Nyquist plots, and (g) charge transfer mechanism of the BO/Ru/CN ternary heterostructured electrode. Reprinted with permission from reference [102], Copyright 2019, American Chemical Society.

Table 2. The PEC performance of $\mathrm{g}-\mathrm{C}_{3} \mathrm{~N}_{4}$-based ternary heterostructured photoelectrodes.

\begin{tabular}{|c|c|c|c|c|c|c|}
\hline Photoelectrodes & $\begin{array}{l}\text { Synthesis } \\
\text { Methods }\end{array}$ & Potential (V) & Electrolytes & $\begin{array}{l}\text { Light } \\
\text { Sources }\end{array}$ & $\begin{array}{l}\text { Photocurrent } \\
\text { Density } \\
\left(\mathrm{mA} \mathrm{cm}^{-2}\right)\end{array}$ & Ref. \\
\hline $\mathrm{ZnO} / \mathrm{Au} / \mathrm{g}-\mathrm{C}_{3} \mathrm{~N}_{4}$ & $\begin{array}{l}\text { Thermal vapor } \\
\text { condensation }\end{array}$ & -0.5 vs. RHE & $0.2 \mathrm{M} \mathrm{Na}_{2} \mathrm{SO}_{4}$ & Solar & -0.29 & [104] \\
\hline $\mathrm{g}-\mathrm{C}_{3} \mathrm{~N}_{4} / \mathrm{Pt} / \mathrm{ZnO}$ & Spin coating & 0.5 vs. $\mathrm{Ag} / \mathrm{AgCl}$ & $0.5 \mathrm{M} \mathrm{Na}_{2} \mathrm{SO}_{4}$ & Solar & 0.12 & [105] \\
\hline
\end{tabular}


Table 2. Cont.

\begin{tabular}{|c|c|c|c|c|c|c|}
\hline Photoelectrodes & $\begin{array}{l}\text { Synthesis } \\
\text { Methods }\end{array}$ & Potential (V) & Electrolytes & $\begin{array}{l}\text { Light } \\
\text { Sources }\end{array}$ & $\begin{array}{l}\text { Photocurrent } \\
\text { Density } \\
\left(\mathrm{mA} \mathrm{cm}^{-2}\right)\end{array}$ & Ref. \\
\hline $\mathrm{g}-\mathrm{C}_{3} \mathrm{~N}_{4} / \mathrm{Ti}-\mathrm{Fe}_{2} \mathrm{O}_{3}$ & Electrodeposition & 0.23 vs. $\mathrm{Ag} / \mathrm{AgCl}$ & $1.0 \mathrm{M} \mathrm{NaOH}$ & Visible & 2.55 & [106] \\
\hline $\mathrm{g}-\mathrm{C}_{3} \mathrm{~N}_{4} / \mathrm{TiN}-\mathrm{NFG}$ & $\begin{array}{l}\text { Ultra-sonication } \\
\text { Hydrothermal, chemical }\end{array}$ & 0.11 vs. RHE & $0.5 \mathrm{M} \mathrm{Na}_{2} \mathrm{SO}_{4}$ & Solar & -0.196 & [107] \\
\hline $\mathrm{TiO}_{2} @ \mathrm{~g}-\mathrm{C}_{3} \mathrm{~N}_{4} / \mathrm{Co}-\mathrm{Pi}$ & $\begin{array}{l}\text { bath deposition, } \\
\text { electrodeposition }\end{array}$ & 1.23 vs. RHE & $0.1 \mathrm{M} \mathrm{Na}_{2} \mathrm{SO}_{4}$ & Solar & 1.6 & [108] \\
\hline $\mathrm{Ag} @ \mathrm{~g}-\mathrm{C}_{3} \mathrm{~N}_{4} / \mathrm{ZnS}$ & $\begin{array}{l}\text { electrophoretic } \\
\text { deposition }\end{array}$ & 1.23 vs. RHE & $0.3 \mathrm{M} \mathrm{KCl}$ & Visible & 0.1 & [109] \\
\hline $\begin{array}{l}\text { Fluorine-dopedg- } \\
\mathrm{C}_{3} \mathrm{~N}_{4} / \mathrm{TiO}_{2}\end{array}$ & In-situ growth & 0.6 vs. $\mathrm{Ag} / \mathrm{AgCl}$ & $0.1 \mathrm{M} \mathrm{KOH}$ & Visible & 0.18 & [110] \\
\hline $\mathrm{Ti}^{3+}-\mathrm{TiO}_{2} / \mathrm{O}-\mathrm{g}-\mathrm{C}_{3} \mathrm{~N}_{4}$ & Hydrothermal & 0.1 vs. $\mathrm{Ag} / \mathrm{AgCl}$ & $0.1 \mathrm{M} \mathrm{Na}_{2} \mathrm{SO}_{4}$ & Visible & 0.0034 & [111] \\
\hline $\mathrm{TiO}_{2} @ \mathrm{P}-\mathrm{C}_{3} \mathrm{~N}_{4} / \mathrm{Co}_{3} \mathrm{O}_{4}$ & $\begin{array}{l}\text { Chemical bath } \\
\text { deposition }\end{array}$ & 1.23 vs. RHE & $0.5 \mathrm{M} \mathrm{Na}_{2} \mathrm{SO}_{4}$ & Visible & 1.58 & [112] \\
\hline $\mathrm{NiFe} / \mathrm{N}-\mathrm{rGO} / \mathrm{g}-\mathrm{C}_{3} \mathrm{~N}_{4}$ & $\begin{array}{l}\text { Calcinations, } \\
\text { electrostatic } \\
\text { self-assembly, and } \\
\text { hydrothermal }\end{array}$ & 0.8 vs. $\mathrm{Ag} / \mathrm{AgCl}$ & $0.1 \mathrm{M} \mathrm{Na}_{2} \mathrm{SO}_{4}$ & Visible & -0.97 & [113] \\
\hline
\end{tabular}

\section{Future Perspectives}

The experimental evidence revealed that $\mathrm{g}-\mathrm{C}_{3} \mathrm{~N}_{4}$-could be used as a photocatalyst and decent catalyst support material for various metal oxide-based heterostructured electrodes fabrication $[29,114]$. However, hybridizing the $g-\mathrm{C}_{3} \mathrm{~N}_{4}$ with a second carbon component could further enhance the overall conductivity of the heterostructured electrodes and the durability of $\mathrm{g}-\mathrm{C}_{3} \mathrm{~N}_{4}$ catalysts $[40,52,115]$. Thus far, experimental investigations indicated that $\mathrm{g}-\mathrm{C}_{3} \mathrm{~N}_{4}$-carbon hybrid catalysts could improve the overall PEC performance.

(i) To further improve the photocatalytic activity and water splitting efficiency, innovative strategies are required to synthesize g- $\mathrm{C}_{3} \mathrm{~N}_{4}$-based heterostructured electrodes with various hierarchical and porous morphologies [70,91,116].

(ii) Most of the reported heterostructured catalysts have been investigated using $g-\mathrm{C}_{3} \mathrm{~N}_{4}$ nanosheet morphologies only. It is worth exploring other morphologies of $g-C_{3} N_{4}$ such as nanorods, nanoparticles, nanotubes, porous nanosheets, etc. [61,64].

(iii) The simultaneous modification of $\mathrm{g}-\mathrm{C}_{3} \mathrm{~N}_{4}$-based heterostructured electrodes through one or more of the following methods: (i) the rational design of nanoarrays architectures, (ii) doping of atoms or molecules, and (iii) loading of various co-catalysts. These strategies can also offer extraordinary improvement of PEC performance due to the synergetic effect of the different catalytic mechanisms $[63,117]$.

(iv) Moreover, the theoretical and computational screening investigations must be performed to elucidate the charge transfer mechanism, PEC water splitting efficiency, stability, and strategies for improving the overall photocatalytic activity of $g-\mathrm{C}_{3} \mathrm{~N}_{4}$ based catalysts.

(v) In addition, these computational studies can serve as a guide for experimentalists, especially for selecting the optimal materials and making their hybrid compositions. Therefore, understanding the effect of materials matrices on water splitting performance is needed. It will also help to develop the other requirements of catalysts, such as stability and cost consumption for the real-time application of the PEC water splitting process.

(vi) Furthermore, electrolytes used in the PEC water splitting have significant influences on the overall PEC performance. Besides, it is also essential to maintain the system at a constant temperature to get accurate PEC measurements. Therefore, it is suggested to utilize water baths or thermostatic systems during the PEC measurements. In addition, a light source should also be equipped with infrared cut-off filters to block the unnecessary heating effect and the evaporation of electrolytes.

\section{Conclusions}

This review summarized and discussed the recent advances in $\mathrm{g}-\mathrm{C}_{3} \mathrm{~N}_{4}$-based binary and ternary heterostructured electrodes for PEC water splitting. The PEC water splitting is the most straightforward and promising way to produce solar fuels, considering the 
safety factor, environmental friendliness, and the abundance of solar energy. The process is usually carried out at room temperature and the usage of inorganic materials, lending the system robustness, which is difficult to achieve with organic-based photocatalytic materials. The g- $\mathrm{C}_{3} \mathrm{~N}_{4}$-based binary and ternary heterostructured electrodes exhibit excellent water splitting performance and stability due to the synergistic interactions with large surface area and facile transportation of charge carriers. There are certain drawbacks associated with PEC water splitting; however, they can be overcome by combining it with the biological processes that are capable of producing a large quantity of hydrogen. The heterostructured electrodes made of $\mathrm{g}-\mathrm{C}_{3} \mathrm{~N}_{4}$ with various binary and ternary semiconductor nanostructured materials are promising photocatalysts in terms of efficient formation of reactive oxygen species and lower recombination of electrons and holes. From the results mentioned above, the ternary $\mathrm{g}-\mathrm{C}_{3} \mathrm{~N}_{4}$-based heterostructured electrodes exhibited superior photocurrent densities with lower $R_{c t}$ value and enlarged visible-light absorption capability when compared to the binary $\mathrm{g}-\mathrm{C}_{3} \mathrm{~N}_{4}$-based heterostructured electrodes. This phenomenon could be attributed to the large surface area, synergistic interfaces among the ternary components with a quick charge carrier transportation, thus eventually reducing the reunion of charge carriers. Apart from the experiments discussed here, the $\mathrm{g}-\mathrm{C}_{3} \mathrm{~N}_{4}$-based heterostructured electrodes can also be used in various concentrations of different electrolytes with a wide range of operating potentials. Experimental studies have revealed that $g-\mathrm{C}_{3} \mathrm{~N}_{4}$-based heterostructured electrodes could act as efficient photocatalyst support materials for PEC water splitting. However, several bottlenecks still exist that can hinder the use of $g-C_{3} N_{4}$ for the PEC water splitting reactions, which needs further elaborative research on this fascinating material and the other $\mathrm{g}-\mathrm{C}_{3} \mathrm{~N}_{4}$-based heterostructured electrode designs.

Author Contributions: Conceptualization and methodology, writing-original draft preparation, R.K.; writing—original draft preparation, S.G.P.; writing—editing, T.G.L.; writing—editing, C.R.M.; writing-editing, D.-Y.L.; resources, J.S.; funding acquisition, writing-review and editing, S.K.B. All authors have read and agreed to the published version of the manuscript.

Funding: This research was supported by the National Research Foundation of Korea (NRF) funded by the Korean Government (2020R1A2C1012439; 2021R1F1A1046648 (MSIT)), Republic of Korea.

Conflicts of Interest: The authors declare that they have no known competing financial interests or personal relationships that could have appeared to influence the work reported in this paper.

\section{References}

1. Siavash Moakhar, R.; Hosseini-Hosseinabad, S.M.; Masudy-Panah, S.; Seza, A.; Jalali, M.; Fallah-Arani, H.; Dabir, F.; Gholipour, S.; Abdi, Y.; Bagheri-Hariri, M.; et al. Photoelectrochemical water-splitting using CuO-based electrodes for hydrogen production: A review. Adv. Mater. 2021, 33, 2007285. [CrossRef] [PubMed]

2. Yu, J.M.; Lee, J.; Kim, Y.S.; Song, J.; Oh, J.; Lee, S.M.; Jeong, M.; Kim, Y.; Kwak, J.H.; Cho, S.; et al. High-performance and stable photoelectrochemical water splitting cell with organic-photoactive-layer-based photoanode. Nat. Commun. 2020, 11, 5509. [CrossRef] [PubMed]

3. Hamdani, I.R.; Bhaskarwar, A.N. Recent progress in material selection and device designs for photoelectrochemical water-splitting. Renew. Sustain. Energy Rev. 2021, 138, 110503. [CrossRef]

4. Cen, J.; Wu, Q.; Liu, M.; Orlov, A. Developing new understanding of photoelectrochemical water splitting via in-situ techniques: A review on recent progress. Green Energy Environ. 2017, 2, 100-111. [CrossRef]

5. Joy, J.; Mathew, J.; George, S.C. Nanomaterials for photoelectrochemical water splitting-Review. Int. J. Hydrogen Energy 2018, 43, 4804-4817. [CrossRef]

6. Yang, W.; Park, J.; Kwon, H.-C.; Hutter, O.S.; Phillips, L.J.; Tan, J.; Lee, H.; Lee, J.; Tilley, S.D.; Major, J.D.; et al. Solar water splitting exceeding $10 \%$ efficiency via low-cost $\mathrm{Sb}_{2} \mathrm{Se}_{3}$ photocathodes coupled with semitransparent perovskite photovoltaics. Energy Environ. Sci. 2020, 13, 4362-4370. [CrossRef]

7. Nadeem, M.A.; Khan, M.A.; Ziani, A.A.; Idriss, H. An overview of the photocatalytic water splitting over suspended particles. Catalysts 2021, 11, 60. [CrossRef]

8. Varadhan, P.; Fu, H.-C.; Kao, Y.-C.; Horng, R.-H.; He, J.-H. An efficient and stable photoelectrochemical system with 9\% solar-to-hydrogen conversion efficiency via InGaP/GaAs double junction. Nat. Commun. 2019, 10, 5282. [CrossRef] [PubMed]

9. Fernández-Climent, R.; Giménez, S.; García-Tecedor, M. The role of oxygen vacancies in water splitting photoanodes. Sustain. Energy Fuels 2020, 4, 5916-5926. [CrossRef] 
10. Elbakkay, M.H.; El Rouby, W.M.A.; El-Dek, S.I.; Farghali, A.A. S-TiO 2 /S-reduced graphene oxide for enhanced photoelectrochemical water splitting. Appl. Surf. Sci. 2018, 439, 1088-1102. [CrossRef]

11. Jian, J.; Sun, J. A review of recent progress on silicon carbide for photoelectrochemical water splitting. Solar RRL 2020, 4, 2000111. [CrossRef]

12. Zheng, G.; Wang, J.; Liu, H.; Murugadoss, V.; Zu, G.; Che, H.; Lai, C.; Li, H.; Ding, T.; Gao, Q.; et al. Tungsten oxide nanostructures and nanocomposites for photoelectrochemical water splitting. Nanoscale 2019, 11, 18968-18994. [CrossRef] [PubMed]

13. Jin, S. What else can photoelectrochemical solar energy conversion do besides water splitting and $\mathrm{CO}_{2}$ reduction? ACS Energy Lett. 2018, 3, 2610-2612. [CrossRef]

14. Wang, S.; Lu, A.; Zhong, C.-J. Hydrogen production from water electrolysis: Role of catalysts. Nano Converg. 2021, 8, 4 [CrossRef] [PubMed]

15. Ke, J.; He, F.; Wu, H.; Lyu, S.; Liu, J.; Yang, B.; Li, Z.; Zhang, Q.; Chen, J.; Lei, L.; et al. Nanocarbon-enhanced 2D photoelectrodes: A new paradigm in photoelectrochemical water splitting. Nanomicro Lett. 2020, 13, 24. [CrossRef] [PubMed]

16. Niu, F.; Wang, D.; Li, F.; Liu, Y.; Shen, S.; Meyer, T.J. Hybrid photoelectrochemical water splitting systems: From interface design to system assembly. Adv. Energy Mater. 2020, 10, 1900399. [CrossRef]

17. Ye, K.-H.; Li, H.; Huang, D.; Xiao, S.; Qiu, W.; Li, M.; Hu, Y.; Mai, W.; Ji, H.; Yang, S. Enhancing photoelectrochemical water splitting by combining work function tuning and heterojunction engineering. Nat. Commun. 2019, 10, 3687. [CrossRef] [PubMed]

18. Ali, M.; Pervaiz, E.; Noor, T.; Rabi, O.; Zahra, R.; Yang, M. Recent advancements in MOF-based catalysts for applications in electrochemical and photoelectrochemical water splitting: A review. Int. J. Energy Res. 2021, 45, 1190-1226. [CrossRef]

19. Tan, H.L.; Abdi, F.F.; Ng, Y.H. Heterogeneous photocatalysts: An overview of classic and modern approaches for optical, electronic, and charge dynamics evaluation. Chem. Soc. Rev. 2019, 48, 1255-1271. [CrossRef]

20. Franchi, D.; Amara, Z. Applications of sensitized semiconductors as heterogeneous visible-light photocatalysts in organic synthesis. ACS Sustain. Chem. Eng. 2020, 8, 15405-15429. [CrossRef]

21. Arunachalam, P.; Nagai, K.; Amer, M.S.; Ghanem, M.A.; Ramalingam, R.J.; Al-Mayouf, A.M. Recent developments in the use of heterogeneous semiconductor photocatalyst based materials for a visible-light-induced water-splitting system-A brief review. Catalysts 2021, 11, 160. [CrossRef]

22. Tang, P.; Arbiol, J. Engineering surface states of hematite based photoanodes for boosting photoelectrochemical water splitting. Nanoscale Horiz. 2019, 4, 1256-1276. [CrossRef]

23. $\mathrm{Wu}, \mathrm{Y}$;; Bi, L. Research progress on catalytic water splitting based on polyoxometalate/semiconductor composites. Catalysts 2021, 11, 524. [CrossRef]

24. Ng, B.-J.; Putri, L.K.; Kong, X.Y.; Teh, Y.W.; Pasbakhsh, P.; Chai, S.-P. Z-scheme photocatalytic systems for solar water splitting. Adv. Sci. 2020, 7, 1903171. [CrossRef]

25. Zou, X.; Sun, Z.; Hu, Y.H. g- $\mathrm{C}_{3} \mathrm{~N}_{4}$-based photoelectrodes for photoelectrochemical water splitting: A review. J. Mater. Chem. A 2020, 8, 21474-21502. [CrossRef]

26. Daulbayev, C.; Sultanov, F.; Bakbolat, B.; Daulbayev, O. 0D, 1D and 2D nanomaterials for visible photoelectrochemical water splitting-A Review. Int. J. Hydrogen Energy 2020, 45, 33325-33342. [CrossRef]

27. Mishra, A.; Mehta, A.; Basu, S.; Shetti, N.P.; Reddy, K.R.; Aminabhavi, T.M. Graphitic carbon nitride (g-C3N4)-based metal-free photocatalysts for water splitting: A review. Carbon 2019, 149, 693-721. [CrossRef]

28. Safaei, J.; Mohamed, N.A.; Mohamad Noh, M.F.; Soh, M.F.; Ludin, N.A.; Ibrahim, M.A.; Roslam Wan Isahak, W.N.; Mat Teridi, M.A. Graphitic carbon nitride $\left(\mathrm{g}-\mathrm{C}_{3} \mathrm{~N}_{4}\right)$ electrodes for energy conversion and storage: A review on photoelectrochemical water splitting, solar cells and supercapacitors. J. Mater. Chem. A 2018, 6, 22346-22380. [CrossRef]

29. Wang, L.; Si, W.; Tong, Y.; Hou, F.; Pergolesi, D.; Hou, J.; Lippert, T.; Dou, S.X.; Liang, J. Graphitic carbon nitride (g-C $\left.3 \mathrm{~N}_{4}\right)$-based nanosized heteroarrays: Promising materials for photoelectrochemical water splitting. Carbon Energy 2020, 2, 223-250. [CrossRef]

30. Wang, S.; Zhang, J.; Li, B.; Sun, H.; Wang, S. Engineered graphitic carbon nitride-based photocatalysts for visible-light-driven water splitting: A review. Energy Fuel 2021, 35, 6504-6526. [CrossRef]

31. Kumar, D.; Sharma, S.; Khare, N. Enhanced photoelectrochemical performance of $\mathrm{NaNbO}_{3}$ nanofiber photoanodes coupled with visible light active $\mathrm{g}-\mathrm{C}_{3} \mathrm{~N}_{4}$ nanosheets for water splitting. Nanotechnology 2020, 31, 135402. [CrossRef] [PubMed]

32. Acharya, R.; Parida, K. A review on $\mathrm{TiO}_{2} / g-\mathrm{C}_{3} \mathrm{~N}_{4}$ visible-light-responsive photocatalysts for sustainable energy generation and environmental remediation. J. Environ. Chem. Eng. 2020, 8, 103896. [CrossRef]

33. Asadzadeh-Khaneghah, S.; Habibi-Yangjeh, A. g- $\mathrm{C}_{3} \mathrm{~N}_{4}$ / carbon dot-based nanocomposites serve as efficacious photocatalysts for environmental purification and energy generation: A review. J. Clean. Prod. 2020, 276, 124319. [CrossRef]

34. Ong, W.-J.; Tan, L.-L.; Ng, Y.H.; Yong, S.-T.; Chai, S.-P. Graphitic carbon nitride $\left(\mathrm{g}_{-} \mathrm{C}_{3} \mathrm{~N}_{4}\right)$-based photocatalysts for artificial photosynthesis and environmental remediation: Are we a step closer to achieving sustainability? Chem. Rev. 2016, 116, 7159-7329. [CrossRef] [PubMed]

35. Ren, Y.; Zeng, D.; Ong, W.-J. Interfacial engineering of graphitic carbon nitride $\left(\mathrm{g}-\mathrm{C}_{3} \mathrm{~N}_{4}\right)$-based metal sulfide heterojunction photocatalysts for energy conversion: A review. Chin. J. Catal. 2019, 40, 289-319. [CrossRef]

36. Kumar, P.; Boukherroub, R.; Shankar, K. Sunlight-driven water-splitting using two-dimensional carbon based semiconductors. J. Mater. Chem. A 2018, 6, 12876-12931. [CrossRef]

37. Reddy, A.S.; Kim, J. An efficient g- $\mathrm{C}_{3} \mathrm{~N}_{4}$-decorated CdS-nanoparticle-doped $\mathrm{Fe}_{3} \mathrm{O}_{4}$ hybrid catalyst for an enhanced $\mathrm{H}_{2}$ evolution through photoelectrochemical water splitting. Appl. Surf. Sci. 2020, 513, 145836. [CrossRef] 
38. Ong, W.-J. 2D/2D graphitic carbon nitride $\left(\mathrm{g}-\mathrm{C}_{3} \mathrm{~N}_{4}\right)$ heterojunction nanocomposites for photocatalysis: Why does face-to-face interface matter? Front. Mater. 2017, 4, 11. [CrossRef]

39. Zhu, B.; Zhang, L.; Cheng, B.; Yu, J. First-principle calculation study of tri-s-triazine-based g-C ${ }_{3} \mathrm{~N}_{4}$ : A review. Appl. Catal. B 2018, 224, 983-999. [CrossRef]

40. Hosseini H., S.M.; Siavash Moakhar, R.; Soleimani, F.; Sadrnezhaad, S.K.; Masudy-Panah, S.; Katal, R.; Seza, A.; Ghane, N.; Ramakrishna, S. One-pot microwave synthesis of hierarchical C-doped $\mathrm{CuO}$ dandelions $/ \mathrm{g}-\mathrm{C}_{3} \mathrm{~N}_{4}$ nanocomposite with enhanced photostability for photoelectrochemical water splitting. Appl. Surf. Sci. 2020, 530, 147271. [CrossRef]

41. Ismael, M. A review on graphitic carbon nitride $\left(\mathrm{g}-\mathrm{C}_{3} \mathrm{~N}_{4}\right)$ based nanocomposites: Synthesis, categories, and their application in photocatalysis. J. Alloys Compd. 2020, 846, 156446. [CrossRef]

42. Tamirat, A.G.; Rick, J.; Dubale, A.A.; Su, W.-N.; Hwang, B.-J. Using hematite for photoelectrochemical water splitting: A review of current progress and challenges. Nanoscale Horiz. 2016, 1, 243-267. [CrossRef] [PubMed]

43. Wang, F.; Li, Q.; Xu, D. Recent progress in semiconductor-based nanocomposite photocatalysts for solar-to-chemical energy conversion. Adv. Energy Mater. 2017, 7, 1700529. [CrossRef]

44. Lui, Y.H.; Zhang, B.; Hu, S. Rational design of photoelectrodes for photoelectrochemical water splitting and $\mathrm{CO}_{2}$ reduction. Front. Phys. 2019, 14, 53402. [CrossRef]

45. Chen, S.; Huang, D.; Xu, P.; Xue, W.; Lei, L.; Cheng, M.; Wang, R.; Liu, X.; Deng, R. Semiconductor-based photocatalysts for photocatalytic and photoelectrochemical water splitting: Will we stop with photocorrosion? J. Mater. Chem. A 2020, 8 , 2286-2322. [CrossRef]

46. Sumesh, C.K.; Peter, S.C. Two-dimensional semiconductor transition metal based chalcogenide based heterostructures for water splitting applications. Dalton Trans. 2019, 48, 12772-12802. [CrossRef] [PubMed]

47. Serpone, N.; Emeline, A.V.; Ryabchuk, V.K.; Kuznetsov, V.N.; Artem'ev, Y.M.; Horikoshi, S. Why do hydrogen and oxygen yields from semiconductor-based photocatalyzed water splitting remain disappointingly low? Intrinsic and extrinsic factors impacting surface redox reactions. ACS Energy Lett. 2016, 1, 931-948. [CrossRef]

48. Gupta, N.M. Factors affecting the efficiency of a water splitting photocatalyst: A perspective. Renew. Sustain. Energy Rev. 2017, 71, 585-601. [CrossRef]

49. Mahzoon, S.; Nowee, S.M.; Haghighi, M. Synergetic combination of $1 \mathrm{D}-2 \mathrm{D}$ g- $\mathrm{C}_{3} \mathrm{~N}_{4}$ heterojunction nanophotocatalyst for hydrogen production via water splitting under visible light irradiation. Renew. Energy 2018, 127, 433-443. [CrossRef]

50. Wang, H.; Li, X.; Yang, J. The g- $\mathrm{C}_{3} \mathrm{~N}_{4} / \mathrm{C}_{2} \mathrm{~N}$ nanocomposite: A g- $\mathrm{C}_{3} \mathrm{~N}_{4}$-based water-splitting photocatalyst with enhanced energy efficiency. ChemPhysChem 2016, 17, 2100-2104. [CrossRef]

51. Yang, X.; Singh, D.; Ahuja, R. Recent advancements and future prospects in ultrathin 2D semiconductor-based photocatalysts for water splitting. Catalysts 2020, 10, 1111. [CrossRef]

52. Yousefzadeh, S.; Fathi, B. Construction of carbon nanotube-g- $\mathrm{C}_{3} \mathrm{~N}_{4}$ nanocomposite photoanode for the enhanced photoelectrochemical activity in water splitting. J. Electroanal. Chem. 2020, 878, 114580. [CrossRef]

53. Patnaik, S.; Sahoo, D.P.; Parida, K. An overview on Ag modified g- $\mathrm{C}_{3} \mathrm{~N}_{4}$ based nanostructured materials for energy and environmental applications. Renew. Sustain. Energy Rev. 2018, 82, 1297-1312. [CrossRef]

54. Sepahvand, H.; Sharifnia, S. Photocatalytic overall water splitting by Z-scheme $\mathrm{g}-\mathrm{C}_{3} \mathrm{~N}_{4} / \mathrm{BiFeO}_{3}$ heterojunction. Int. J. Hydrogen Energy 2019, 44, 23658-23668. [CrossRef]

55. Yang, Y.; Wang, S.; Li, Y.; Wang, J.; Wang, L. Strategies for efficient solar water splitting using carbon nitride. Chem. Asian J. 2017, 12, 1421-1434. [CrossRef]

56. Gandamalla, A.; Manchala, S.; Anand, P.; Fu, Y.-P.; Shanker, V. Development of versatile $\mathrm{CdMoO}_{4} / \mathrm{g}-\mathrm{C}_{3} \mathrm{~N}_{4}$ nanocomposite for enhanced photoelectrochemical oxygen evolution reaction and photocatalytic dye degradation applications. Mat. Today Chem. 2021, 19, 100392. [CrossRef]

57. Paul, A.M.; Sajeev, A.; Nivetha, R.; Gothandapani, K.; Bhardwaj, P.; Govardhan, K.; Raghavan, V.; Jacob, G.; Sellapan, R.; Jeong, S.K.; et al. Cuprous oxide $\left(\mathrm{Cu}_{2} \mathrm{O}\right)$ /graphitic carbon nitride $\left(\mathrm{g}-\mathrm{C}_{3} \mathrm{~N}_{4}\right)$ nanocomposites for electrocatalytic hydrogen evolution reaction. Diam. Relat. Mater. 2020, 107, 107899. [CrossRef]

58. Fu, J.; Yu, J.; Jiang, C.; Cheng, B. g- $\mathrm{C}_{3} \mathrm{~N}_{4}$-based heterostructured photocatalysts. Adv. Energy Mater. 2018, 8, 1701503. [CrossRef]

59. Zhang, L.; Zhang, M.; Song, X.; Wang, H.; Bian, Z. One-step synthesis of $\mathrm{MnOx} / \mathrm{g}-\mathrm{C}_{3} \mathrm{~N}_{4}$ nanocomposites for enhancing the visible light photoelectrochemical oxidation performance. Chem. Eng. J. 2020, 399, 125825. [CrossRef]

60. Wang, J.; Yang, Z.; Gao, X.; Yao, W.; Wei, W.; Chen, X.; Zong, R.; Zhu, Y. Core-shell g- $\mathrm{C}_{3} \mathrm{~N}_{4} @ Z$ ZnO composites as photoanodes with double synergistic effects for enhanced visible-light photoelectrocatalytic activities. Appl. Catal. B 2017, 217, 169-180. [CrossRef]

61. Xiao, L.; Liu, T.; Zhang, M.; Li, Q.; Yang, J. Interfacial construction of zero-dimensional/one-dimensional g- $\mathrm{C}_{3} \mathrm{~N}_{4}$ nanoparticles $/ \mathrm{TiO}_{2}$ nanotube arrays with Z-scheme heterostructure for improved photoelectrochemical water splitting. ACS Sustain. Chem. Eng. 2019, 7, 2483-2491. [CrossRef]

62. Reddy, C.V.; Koutavarapu, R.; Reddy, I.N.; Shim, J. Effect of a novel one-dimensional zinc tungsten oxide nanorods anchored two-dimensional graphitic carbon nitride nanosheets for improved solar-light-driven photocatalytic removal of toxic pollutants and photoelectrochemical water splitting. J. Mat. Sci. Mat. El. 2021, 32, 33-46. [CrossRef]

63. Seza, A.; Soleimani, F.; Naseri, N.; Soltaninejad, M.; Montazeri, S.M.; Sadrnezhaad, S.K.; Mohammadi, M.R.; Moghadam, H.A.; Forouzandeh, M.; Amin, M.H. Novel microwave-assisted synthesis of porous $\mathrm{g}-\mathrm{C}_{3} \mathrm{~N}_{4} / \mathrm{SnO} \mathrm{O}_{2}$ nanocomposite for solar water-splitting. Appl. Surf. Sci. 2018, 440, 153-161. [CrossRef] 
64. Bakr, A.E.A.; El Rouby, W.M.A.; Khan, M.D.; Farghali, A.A.; Xulu, B.; Revaprasadu, N. Synthesis and characterization of Z-scheme $\alpha-\mathrm{Fe}_{2} \mathrm{O}_{3} \mathrm{NTs}$ /ruptured tubular $\mathrm{g}-\mathrm{C}_{3} \mathrm{~N}_{4}$ for enhanced photoelectrochemical water oxidation. Sol. Energy 2019, 193, 403-412. [CrossRef]

65. Alam, K.M.; Kumar, P.; Kar, P.; Thakur, U.K.; Zeng, S.; Cui, K.; Shankar, K. Enhanced charge separation in g-C $\mathrm{N}_{4}-\mathrm{BiOI}$ heterostructures for visible light driven photoelectrochemical water splitting. Nanoscale Adv. 2019, 1, 1460-1471. [CrossRef]

66. Liu, C.; Wang, F.; Zhang, J.; Wang, K.; Qiu, Y.; Liang, Q.; Chen, Z. Efficient photoelectrochemical water splitting by g- $\mathrm{C}_{3} \mathrm{~N}_{4} / \mathrm{TiO}_{2}$ nanotube array heterostructures. Nanomicro Lett. 2018, 10, 37. [CrossRef]

67. Liu, Y.; Yu, Y.-X.; Zhang, W.-D. Photoelectrochemical study on charge transfer properties of nanostructured $\mathrm{Fe}_{2} \mathrm{O}_{3}$ modified by $\mathrm{g}-\mathrm{C}_{3} \mathrm{~N}_{4}$. Int. J. Hydrogen Energy 2014, 39, 9105-9113. [CrossRef]

68. Lei, N.; Li, J.; Song, Q.; Liang, Z. Construction of g- $\mathrm{C}_{3} \mathrm{~N}_{4} / \mathrm{BCN}$ two-dimensional heterojunction photoanode for enhanced photoelectrochemical water splitting. Int. J. Hydrogen Energy 2019, 44, 10498-10507. [CrossRef]

69. Murugan, C.; Bhojanaa, K.B.; Ong, W.-J.; Jothivenkatachalam, K.; Pandikumar, A. Improving hole mobility with the heterojunction of graphitic carbon nitride and titanium dioxide via soft template process in photoelectrocatalytic water splitting. Int. J. Hydrogen Energy 2019, 44, 30885-30898. [CrossRef]

70. Murugan, C.; Karnan, M.; Sathish, M.; Pandikumar, A. Construction of heterostructure based on hierarchical $\mathrm{Bi}_{2} \mathrm{MoO}_{6}$ and $\mathrm{g}-\mathrm{C}_{3} \mathrm{~N}_{4}$ with ease for impressive performance in photoelectrocatalytic water splitting and supercapacitor. Catal. Sci. Technol. 2020, 10, 2427-2442. [CrossRef]

71. Mohammad, A.; Khan, M.E.; Karim, M.R.; Cho, M.H. Synergistically effective and highly visible light responsive $\mathrm{SnO}_{2}-\mathrm{g}_{-} \mathrm{C}_{3} \mathrm{~N}_{4}$ nanostructures for improved photocatalytic and photoelectrochemical performance. Appl. Surf. Sci. 2019, 495, 143432. [CrossRef]

72. Hao, H.; Lu, D.; Wang, Q. Photoelectrochemical study on charge separation mechanisms of $\mathrm{Bi}_{2} \mathrm{WO}_{6}$ quantum dots decorated g- $\mathrm{C}_{3} \mathrm{~N}_{4}$. Int. J. Hydrogen Energy 2018, 43, 8824-8834. [CrossRef]

73. Mahala, C.; Sharma, M.D.; Basu, M. ZnO nanosheets decorated with graphite-like carbon nitride quantum dots as photoanodes in photoelectrochemical water splitting. ACS Appl. Nano Mater. 2020, 3, 1999-2007. [CrossRef]

74. Ma, X.; Zhang, J.; Wang, B.; Li, Q.; Chu, S. Hierarchical $\mathrm{Cu}_{2} \mathrm{O}$ foam/g- $\mathrm{C}_{3} \mathrm{~N}_{4}$ photocathode for photoelectrochemical hydrogen production. Appl. Surf. Sci. 2018, 427, 907-916. [CrossRef]

75. Liu, Y.; Zhang, J.; Li, X.; Yao, Z.; Zhou, L.; Sun, H.; Wang, S. Graphitic carbon nitride decorated with CoP nanocrystals for enhanced photocatalytic and photoelectrochemical $\mathrm{H}_{2}$ evolution. Energy Fuel 2019, 33, 11663-11676. [CrossRef]

76. Murugan, C.; Abinav Nataraj, R.; Praveen Kumar, M.; Ravichandran, S.; Pandikumar, A. Enhanced charge transfer process of bismuth vanadate interleaved graphitic carbon nitride nanohybrids in mediator-free direct Z-scheme photoelectrocatalytic water splitting. Chem. Sel. 2019, 4, 4653-4663. [CrossRef]

77. Wang, R.; Yan, J.; Zu, M.; Yang, S.; Cai, X.; Gao, Q.; Fang, Y.; Zhang, S.; Zhang, S. Facile synthesis of interlocking g-C $3 \mathrm{~N}_{4} / \mathrm{CdS}$ photoanode for stable photoelectrochemical hydrogen production. Electrochim. Acta 2018, 279, 74-83. [CrossRef]

78. Miao, H.; Zhang, G.; Hu, X.; Mu, J.; Han, T.; Fan, J.; Zhu, C.; Song, L.; Bai, J.; Hou, X. A novel strategy to prepare 2D g-C ${ }_{3} N_{4}$ nanosheets and their photoelectrochemical properties. J. Alloys Compd. 2017, 690, 669-676. [CrossRef]

79. Bian, H.; Wang, A.; Li, Z.; Li, Z.; Diao, Y.; Lu, J.; Li, Y.Y. g- $\mathrm{C}_{3} \mathrm{~N}_{4}$-modified water-crystallized mesoporous $\mathrm{SnO}_{2}$ for enhanced photoelectrochemical properties. Part. Part. Syst. Charact. 2018, 35, 1800155. [CrossRef]

80. Jiang, T.; Nan, F.; Zhou, J.; Zheng, F.; Weng, Y.; Cai, T.-Y.; Ju, S.; Xu, B.; Fang, L. Enhanced photocatalytic and photoelectrochemical performance of $\mathrm{g}-\mathrm{C}_{3} \mathrm{~N}_{4} / \mathrm{BiVO}_{4}$ heterojunction: A combined experimental and theoretical study. AIP Adv. 2019, 9, 055225. [CrossRef]

81. Sariket, D.; Ray, D.; Baduri, S.; Ghosh, S.; Maity, A.; Bhattacharya, C. Synthesis of g- $\mathrm{C}_{3} \mathrm{~N}_{4} / \mathrm{InVO}_{4}$ semiconductor for improved photocatalytic and photoelectrochemical applications. Electroanalysis 2020, 32, 2535-2544. [CrossRef]

82. Kokane, S.B.; Sasikala, R.; Phase, D.M.; Sartale, S.D. $\operatorname{In}_{2} \mathrm{~S}_{3}$ nanoparticles dispersed on g- $\mathrm{C}_{3} \mathrm{~N}_{4}$ nanosheets: Role of heterojunctions in photo-induced charge transfer and photoelectrochemical and photocatalytic performance. J. Mater. Sci. 2017, 52, 7077-7090. [CrossRef]

83. Zhang, S.; Yan, J.; Yang, S.; Xu, Y.; Cai, X.; Li, X.; Zhang, X.; Peng, F.; Fang, Y. Electrodeposition of Cu ${ }_{2} \mathrm{O} / \mathrm{g}-\mathrm{C}_{3} \mathrm{~N}_{4}$ heterojunction film on an FTO substrate for enhancing visible light photoelectrochemical water splitting. Chin. J. Catal. 2017, 38, 365-371. [CrossRef]

84. Wu, F.; Ma, Y.; Hu, Y.H. Near infrared light-driven photoelectrocatalytic water splitting over P-doped g-C $3 \mathrm{~N}_{4}$. ACS Appl. Energy Mater. 2020, 3, 11223-11230. [CrossRef]

85. Safaei, J.; Ullah, H.; Mohamed, N.A.; Mohamad Noh, M.F.; Soh, M.F.; Tahir, A.A.; Ahmad Ludin, N.; Ibrahim, M.A.; Wan Isahak, W.N.R.; Mat Teridi, M.A. Enhanced photoelectrochemical performance of Z-scheme g- $\mathrm{C}_{3} \mathrm{~N}_{4} / \mathrm{BiVO}_{4}$ photocatalyst. Appl. Catal. B 2018, 234, 296-310. [CrossRef]

86. Ragupathi, V.; Raja, M.A.; Panigrahi, P.; Ganapathi Subramaniam, N. CuO/g- $\mathrm{C}_{3} \mathrm{~N}_{4}$ nanocomposite as promising photocatalyst for photoelectrochemical water splitting. Optik 2020, 208, 164569. [CrossRef]

87. Xiaoyi, H.; Xiangkang, Z.; Yue, L.; Jun, L.; Shi, Y.; Yichun, Y.; Jian, H.; David, T.M.; Xiwang, Z. Nano-layer based 1T-rich $\mathrm{MoS}_{2} / \mathrm{g}-\mathrm{C}_{3} \mathrm{~N}_{4}$ co-catalyst system for enhanced photocatalytic and photoelectrochemical activity. Appl. Catal. B 2020, $268,118466$.

88. Guru, S.; Kumar, S.; Bellamkonda, S.; Gangavarapu, R.R. Synthesis of CuTi-LDH supported on g- $\mathrm{C}_{3} \mathrm{~N}_{4}$ for electrochemical and photoelectrochemical oxygen evolution reactions. Int. J. Hydrogen Energy 2021, 46, 16414-16430. [CrossRef]

89. Guigoz, V.; Balan, L.; Aboulaich, A.; Schneider, R.; Gries, T. Heterostructured thin $\mathrm{LaFeO}_{3} / \mathrm{g}-\mathrm{C}_{3} \mathrm{~N}_{4}$ films for efficient photoelectrochemical hydrogen evolution. Int. J. Hydrogen Energy 2020, 45, 17468-17479. [CrossRef] 
90. Chen, Z.; Ma, G.; Chen, Z.; Zhang, Y.; Zhang, Z.; Gao, J.; Meng, Q.; Yuan, M.; Wang, X.; Liu, J.-M.; et al. Fabrication and photoelectrochemical properties of silicon nanowires/g- $\mathrm{C}_{3} \mathrm{~N}_{4}$ core/shell arrays. Appl. Surf. Sci. 2017, 396, 609-615. [CrossRef]

91. Babu, B.; Shim, J.; Yoo, K. Efficient solar-light-driven photoelectrochemical water oxidation of one-step in-situ synthesized Co-doped g- $\mathrm{C}_{3} \mathrm{~N}_{4}$ nanolayers. Ceram. Int. 2020, 46, 16422-16430. [CrossRef]

92. Arif, M.; Yasin, G.; Shakeel, M.; Mushtaq, M.A.; Ye, W.; Fang, X.; Ji, S.; Yan, D. Hierarchical CoFe-layered double hydroxide and g- $\mathrm{C}_{3} \mathrm{~N}_{4}$ heterostructures with enhanced bifunctional photo/electrocatalytic activity towards overall water splitting. Mater. Chem. Front. 2019, 3, 520-531. [CrossRef]

93. Fang, Y.; Huang, W.; Yang, S.; Zhou, X.; Ge, C.; Gao, Q.; Fang, Y.; Zhang, S. Facile synthesis of anatase $/ \mathrm{rutile} \mathrm{TiO}_{2} / \mathrm{g}^{-\mathrm{C}_{3} \mathrm{~N}_{4}}$ multi-heterostructure for efficient photocatalytic overall water splitting. Int. J. Hydrogen Energy 2020, 45, 17378-17387. [CrossRef]

94. Bhandary, N.; Singh, A.P.; Kumar, S.; Ingole, P.P.; Thakur, G.S.; Ganguli, A.K.; Basu, S. In-situ solid-state synthesis of a $\mathrm{AgNi} / \mathrm{g}-\mathrm{C}_{3} \mathrm{~N}_{4}$ nanocomposite for enhanced photoelectrochemical and photocatalytic activity. ChemSusChem 2016, 9, $2816-2823$. [CrossRef] [PubMed]

95. Liu, W.; Shen, J.; Yang, X.; Liu, Q.; Tang, H. Dual Z-scheme g- $\mathrm{C}_{3} \mathrm{~N}_{4} / \mathrm{Ag}_{3} \mathrm{PO}_{4} / \mathrm{Ag}_{2} \mathrm{MoO}_{4}$ ternary composite photocatalyst for solar oxygen evolution from water splitting. Appl. Surf. Sci. 2018, 456, 369-378. [CrossRef]

96. Babu, B.; Koutavarapu, R.; Shim, J.; Yoo, K. Enhanced visible-light-driven photoelectrochemical and photocatalytic performance of $\mathrm{Au}-\mathrm{SnO}_{2}$ quantum dot-anchored g- $\mathrm{C}_{3} \mathrm{~N}_{4}$ nanosheets. Sep. Pur. Technol. 2020, 240, 116652. [CrossRef]

97. Li, J.; Yuan, H.; Zhu, Z. Improved photoelectrochemical performance of Z-scheme g- $\mathrm{C}_{3} \mathrm{~N}_{4} / \mathrm{Bi}_{2} \mathrm{O}_{3} / \mathrm{BiPO}_{4}$ heterostructure and degradation property. Appl. Surf. Sci. 2016, 385, 34-41. [CrossRef]

98. Chaudhary, D.; Kumar, S.; Khare, N. Boosting the visible-light photoelectrochemical performance of $\mathrm{C}_{3} \mathrm{~N}_{4}$ by coupling with TiO and carbon nanotubes: An organic/inorganic hybrid photocatalyst nanocomposite for photoelectrochemical water spitting. Int. J. Hydrogen Energy 2020, 45, 30091-30100. [CrossRef]

99. Si, H.; Deng, Q.; Yin, C.; Tavakoli, M.M.; Zhang, J.; Kong, J. Graphdiyne coupled with g- $\mathrm{C}_{3} \mathrm{~N}_{4} /$ NiFe-layered double hydroxide, a layered nanohybrid for highly efficient photoelectrochemical water oxidation. Adv. Mater. Inter. 2020, 7, 1902083. [CrossRef]

100. Gopalakrishnan, S.; Bhalerao, G.M.; Jeganathan, K. $\mathrm{SrTiO}_{3} \mathrm{NPs} / \mathrm{g}-\mathrm{C}_{3} \mathrm{~N}_{4} \mathrm{NSs}$ coupled Si NWs based hybrid photocathode for visible light driven photoelectrochemical water reduction. ACS Sustain. Chem. Eng. 2019, 7, 13911-13919. [CrossRef]

101. Alam, K.M.; Kumar, P.; Kar, P.; Goswami, A.; Thakur, U.K.; Zeng, S.; Vahidzadeh, E.; Cui, K.; Shankar, K. Heterojunctions of halogen-doped carbon nitride nanosheets and BiOI for sunlight-driven water-splitting. Nanotechnology 2019, 31, 084001. [CrossRef]

102. Wu, Y.; Song, M.; Chai, Z.; Wang, X. Assembling $\mathrm{Bi}_{2} \mathrm{MoO}_{6} / \mathrm{Ru} / \mathrm{g}-\mathrm{C}_{3} \mathrm{~N}_{4}$ for highly effective oxygen generation from water splitting under visible-light irradiation. Inorg. Chem. 2019, 58, 7374-7384. [CrossRef] [PubMed]

103. Patnaik, S.; Swain, G.; Parida, K.M. Highly efficient charge transfer through a double Z-scheme mechanism by a Cu-promoted $\mathrm{MoO}_{3} / \mathrm{g}-\mathrm{C}_{3} \mathrm{~N}_{4}$ hybrid nanocomposite with superior electrochemical and photocatalytic performance. Nanoscale 2018, 10, 59505964. [CrossRef] [PubMed]

104. Wen, P.; Sun, Y.; Li, H.; Liang, Z.; Wu, H.; Zhang, J.; Zeng, H.; Geyer, S.M.; Jiang, L. A highly active three-dimensional Z-scheme $\mathrm{ZnO} / \mathrm{Au} / \mathrm{g}-\mathrm{C}_{3} \mathrm{~N}_{4}$ photocathode for efficient photoelectrochemical water splitting. Appl. Catal. B 2020, 263, 118180. [CrossRef]

105. Xiao, J.; Zhang, X.; Li, Y. A ternary $g-\mathrm{C}_{3} \mathrm{~N}_{4} / \mathrm{Pt} / \mathrm{ZnO}$ photoanode for efficient photoelectrochemical water splitting. Int. J. Hydrogen Energy 2015, 40, 9080-9087. [CrossRef]

106. Liu, Y.; Su, F.-Y.; Yu, Y.-X.; Zhang, W.-D. Nano g- $\mathrm{C}_{3} \mathrm{~N}_{4}$ modified Ti-Fe $\mathrm{O}_{3}$ vertically arrays for efficient photoelectrochemical generation of hydrogen under visible light. Int. J. Hydrogen Energy 2016, 41, 7270-7279. [CrossRef]

107. Shanker, G.S.; Bhosale, R.; Ogale, S.; Nag, A. 2D nanocomposite of g- $\mathrm{C}_{3} \mathrm{~N}_{4}$ and TiN embedded N-doped graphene for photoelectrochemical reduction of water using sunlight. Adv. Mater. Inter. 2018, 5, 1801488. [CrossRef]

108. Li, Y.; Wang, R.; Li, H.; Wei, X.; Feng, J.; Liu, K.; Dang, Y.; Zhou, A. Efficient and stable photoelectrochemical seawater splitting with $\mathrm{TiO}_{2} @ g-\mathrm{C}_{3} \mathrm{~N}_{4}$ nanorod arrays decorated by Co-Pi. J. Phys. Chem. C 2015, 119, 20283-20292. [CrossRef]

109. Mahvelati-Shamsabadi, T.; Goharshadi, E.K.; Karimi-Nazarabad, M. Z-scheme design of Ag@g- $\mathrm{C}_{3} \mathrm{~N}_{4} / \mathrm{ZnS}$ photoanode device for efficient solar water oxidation: An organic-inorganic electronic interface. Int. J. Hydrogen Energy 2019, 4, 13085-13097. [CrossRef]

110. Kumar, P.; Thakur, U.K.; Alam, K.; Kar, P.; Kisslinger, R.; Zeng, S.; Patel, S.; Shankar, K. Arrays of TiO 2 nanorods embedded with fluorine doped carbon nitride quantum dots (CNFQDs) for visible light driven water splitting. Carbon 2018, 137, 174-187. [CrossRef]

111. Li, K.; Huang, Z.; Zeng, X.; Huang, B.; Gao, S.; Lu, J. Synergetic effect of Ti3+ and oxygen doping on enhancing photoelectrochemical and photocatalytic properties of $\mathrm{TiO}_{2} / \mathrm{g}-\mathrm{C}_{3} \mathrm{~N}_{4}$ heterojunctions. ACS Appl. Mater. Inter. 2017, 9, 11577-11586. [CrossRef] [PubMed]

112. Yu, Z.; Li, Y.; Qu, J.; Zheng, R.; Cairney, J.M.; Zhang, J.; Zhu, M.; Khan, A.; Li, W. Enhanced photoelectrochemical water-splitting performance with a hierarchical heterostructure: $\mathrm{Co}_{3} \mathrm{O}_{4}$ nanodots anchored $\mathrm{TiO}_{2} @ \mathrm{P}-\mathrm{C}_{3} \mathrm{~N}_{4}$ core-shell nanorod arrays. Chem. Eng. J. 2021, 404, 126458. [CrossRef]

113. Nayak, S.; Parida, K.M. Deciphering Z-scheme charge transfer dynamics in heterostructure NiFe-LDH/N-rGO/g-C 3 N 4 nanocomposite for photocatalytic pollutant removal and water splitting reactions. Sci. Rep. 2019, 9, 2458. [CrossRef]

114. Naseer, I.; Adeel, A.; Ibrahim, K.; Muhammad, S.K.; Ahsanulhaq, Q. Molybdenum impregnated g-C3N4 nanotubes as potentially active photocatalyst for renewable energy applications. Sci. Rep. 2021, 11, 16886. 
115. Guangqing, L.; Mengwei, X.; Qinpu, L.; Hui, Y.; Yuming, Z. Facile synthesis of C-doped hollow spherical g- $\mathrm{C}_{3} \mathrm{~N}_{4}$ from supramolecular self-assembly for enhanced photoredox water splitting. Int. J. Hydrogen Energy 2019, 44, 25671-25679.

116. Ahmed, E.A.A.; Waleed, M.A.E.R.; Malik, D.K.; Ahmed, A.F.; Neerish, R. ZnCr-CO $\mathrm{C}_{3} \mathrm{LDH} /$ ruptured tubular g-C $\mathrm{N}_{3} \mathrm{Composite}$ with increased specific surface area for enhanced photoelectrochemical water splitting. Appl. Surf. Sci. 2020, $508,145100$.

117. Fazal, R.; Muhammad, H.; Asad, A.; Tingting, W.; Abbas, K.; Qiuyun, F.; Wei, L.; Heping, Z.; Zhiping, Z.; Bilawal, K.; et al. Synthesis of S-Doped porous $\mathrm{g}-\mathrm{C}_{3} \mathrm{~N}_{4}$ by using ionic liquids and subsequently coupled with $\mathrm{Au}-\mathrm{TiO}_{2}$ for exceptional cocatalyst-free visible-light catalytic activities. Appl. Catal. B 2018, 237, 1082-1090. 